\title{
Title: Positive Schizotypy and the Experience of Creativity: The Distinctive Roles of Suspiciousness and Dispositional Mindfulness
}

Heather McDonald ${ }^{\text {a }}$, Mariam Babunashvili ${ }^{\text {a }}$, Ariane Finn ${ }^{\mathrm{a}}$, Aiyana Willard ${ }^{\mathrm{b}}$, Lucia Valmaggia ${ }^{\text {a, c }}$, Paul Chadwick ${ }^{\mathrm{d}}$, Elena Antonova*a, b

a Department of Psychology, Institute of Psychiatry, Psychology and Neuroscience, King's College London, UK

${ }^{\mathrm{b}}$ Division of Psychology, Department of Life Sciences and Centre for Cognitive Neuroscience, College of Health and Life Sciences, Brunel University London, UK

c South London and Maudsley NHS Trust, London, UK

${ }^{\mathrm{d}}$ Department of Psychology, Bath Centre for Mindfulness and Compassion, University of Bath, UK

* Corresponding author:

Elena Antonova

Room GASK259, Gaskell Building

Division of Psychology

Department of Life Sciences

College of Health and Life Sciences

Brunel University London

Uxbridge

UB8 3PH

United Kingdom

elena.antonova@brunel.ac.uk

Abstract: 250 words

Main text: 4,363 words (excluding a footnote, conflict of interest statement, acknowledgements, contributions, and references)

Main text tables: 3

Main text Figures: 2

Supplementary Materials: Tables: 6; Figures: 2 


\begin{abstract}
Positive schizotypy has been shown to predict emergence of schizophrenia-spectrum disorders, with suspiciousness/paranoia regarded a key risk factor. However, magical thinking and unusual perceptual experiences, other aspects of positive schizotypy, are associated with creativity. We investigated whether suspiciousness attenuates the relationship of magical thinking and unusual experiences with creativity experience, and explored the interaction of dispositional mindfulness with positive schizotypy and creative experience. 342 (256 females) healthy adults (mean age: 25.9; SD 8.4) completed online self-report measures of schizotypy, creative experience, and dispositional mindfulness. Moderation analysis showed that suspiciousness attenuated the positive relationship of magical thinking $(b=-.29, p=.03)$ and unusual perceptual experiences $(b=-.23, p=.01)$ with an aspect of creative experience related to positive affect - power/pleasure. This effect was not present for 4 other aspects of creative experience. Multiple linear regressions revealed higher dispositional mindfulness to interact with aspects of positive schizotypy associated with heightened creative experience of power/pleasure $(b=.06, p=.03)$, clarity/preparation $(b=.03, p=.004)$, and differing levels of anxiety associate with creative engagement $(b=-.06, p=.003 ; b=.03, p=.047)$. Higher dispositional mindfulness was also associated with lower suspiciousness $\left(r_{s}=-.33, p<.001\right)$. The study highlights the importance of considering the role of suspiciousness/paranoia when investigating the relationship between positive schizotypy and creativity. The findings provide support for the application of mindfulness-based interventions for mitigating psychosis-risk associated with suspiciousness, whilst supporting the otherwise favourable association of positive schizotypy with creativity.
\end{abstract}

Keywords: schizotypy; schizophrenia; psychosis; paranoia; dispositional mindfulness; creativity 


\section{Introduction}

Schizotypy refers to a set of personality traits found in the general population, with most evidence supporting a three-factor structure corresponding to symptom dimensions of schizophrenia: positive, negative, and disorganised (Mason et al., 1997; Nelson et al., 2013). Schizotypy shows a substantial overlap with schizophrenia across multiple cognitive, behavioural, and neurobiological domains (Ettinger et al., 2014), reflecting a latent predisposition to schizophrenia (Lenzenweger, 2015); however, schizotypal traits can also exist as a normative aspect of personality and do not invariably lead to schizophreniaspectrum disorders.

Positive schizotypy in particular is thought to predict later emergence of schizophreniaspectrum disorders (Debbané et al., 2015; Kwapil et al., 2013), with suspiciousness/paranoia - an aspect of positive schizotypy - being a key risk-factor to psychosis conversion (Wilcox et al., 2014), especially in high-risk individuals (Salokangas et al., 2013). However, another side of the coin of positive schizotypy is the association with heightened creativity - a highly beneficial trait, for both an individual and society. A range of approaches have been used to investigate this link, including assessing self-rated creative achievement (e.g. Polner et al., 2015), self-rated creative ability/behaviour (e.g. Batey \& Furnham, 2008), holding a creative profession (e.g., Nettle \& Clegg, 2006), or assessing creativity using objective tests (e.g., Fink et al., 2014; Rawlings \& Locarnini, 2008). Whilst some studies have reported a link between creativity and positive schizotypy (for a meta-analysis, see Acar \& Sen, 2013), others have not observed it when using the same assessments of schizotypy and creativity (e.g., Michalica \& Hunt, 2013; Rybakowski \& Klonowska, 2011).

The most widely used self-report measures of positive schizotypy in creativity research are the Oxford-Liverpool Inventory for Feelings and Experiences (O-LIFE; Mason et al., 1995) and the Schizotypal Personality Questionnaire (SPQ; Raine, 1991). Both encapsulate magical thinking and unusual perceptual experiences as aspects of positive schizotypy; however, only the SPQ has a subscale measuring suspiciousness/paranoia (referred to as Suspiciousness or Suspiciousness/Paranoid Ideations, Raine 1991). Studies using the SPQ tend to consider positive schizotypy overall, rather than examining separate sub-scales (e.g., Fink et al., 2014; Gibson et al., 2009; Rominger et al., 2014). However, suspiciousness/paranoia may overlap with negative schizotypy (Raine et al., 1994; Kwapil et al., 2013), a dimension which may have differing or even inverse relationship with creativity (Acar \& Sen, 2013). Further, 
paranoia is predicted by cognitive inflexibility (Freeman et al., 2008) - contrary to what is conducive to creativity (Nijstad et al., 2010). It is therefore possible that suspiciousness/paranoia could have an attenuating effect on the relationship between creativity and the aspects of positive schizotypy which have been previously linked to heightened creativity (namely magical thinking and unusual experiences), confounding results of previous research. Given that a larger proportion of the studies using the SPQ/SPQbrief version (Raine \& Benishay, 1995) have reported negative findings on the positive schizotypy and creativity relationship than those using O-LIFE (with a larger number of studies to use O-LIFE overall), an investigation of the role of suspiciousness/paranoia in the relationship between positive schizotypy and creativity is warranted.

Understanding the role of suspiciousness/paranoia in the relationship between positive schizotypy and creativity might have a direct bearing on psychosis prevention strategies. Our recent research suggests that training in mindfulness, a present-moment receptive awareness promoting openness, non-judgement and non-reactivity towards experience (Bishop et al., 2004), might contribute to prevention. We have found that experienced mindfulness meditators score higher on Magical Thinking but lower on Suspiciousness subscales of the SPQ than the general population (Antonova et al., 2016), showing a dissociation between the aspects of positive schizotypy associated with creativity and psychosis risk, respectively. Moreover, experienced meditators show attenuated sensory filtering as compared with healthy controls (Antonova et al., 2015), a sensory information processing feature linked to higher real-world creative achievement (Zabelina et al, 2015). Together, these findings suggest that mindfulness might be protective against the aspects of positive schizotypy that present high risk for psychosis, namely suspiciousness/paranoia, in the presence of factors associated with heightened creative ability such as magical thinking and attenuated sensory information filtering. A one-week mindfulness-based intervention was found to reduce paranoia in university students (Kingston et al., 2019), confirming that paranoia is amenable to mindfulness training.

Whilst mindfulness can be developed as a skill through practices such as meditation, it has also been shown to be a normally distributed personality trait (Baer et al., 2006). It is, therefore, plausible that dispositional mindfulness might have a differential relationship with the aspects of positive schizotypy, specifically magical thinking and suspiciousness/paranoia, and thus impact the relationship between different aspects of positive schizotypy and creativity. However, the inter-relationship between positive schizotypy, creativity and 
dispositional mindfulness is presently unknown, whilst being needed to inform and provide impetus for future research into using mindfulness training for psychosis prevention in individuals at risk.

Based on the previous research and above considerations, the main aims of the present study were novel and two-fold: i) to investigate whether the relationship between the aspects of positive schizotypy previously linked to heightened creativity - specifically, magical thinking and unusual experiences - and creative experience is attenuated by suspiciousness/paranoia; and ii) to explore whether dispositional mindfulness interacts differentially with different aspects of positive schizotypy (magical thinking and unusual experiences vs suspiciousness/paranoia) in their relationship with creative experience.

\section{Methods}

\subsection{Participants}

Three-hundred and forty-two ( 256 females; 84 males; 2 did not disclose) healthy volunteers aged 18-65 (mean age 25.9 years; $\mathrm{SD}=8.4$, range: 18-61) were recruited via London-based universities, creative Facebook groups and local forums. Participants were asked to confirm (via checkbox in the survey) that they met the following inclusion criteria: i) fluency in English; ii) no history or current diagnosis of a mental illness, neurodevelopmental or neurological disorders (as diagnosed by a professional health practitioner, neurologist, psychiatrist or psychologist), or iii) no history of or current substance abuse.

\subsection{Design and Procedures}

A cross-sectional online survey was conducted using via 'Bristol Online Surveys' platform. The study was advertised as 'Investigating the relationship between creativity, mindfulness and personality traits' to circumvent stigma associated with the term schizotypy due to its association with psychopathology. Completion of the survey constituted consent for study participation and $£ 5$ Amazon vouchers were given as remuneration.

The study was approved by the King's College London Research Ethics Committee (LRS17/18-5604). 


\subsection{Self-report measures}

For the description of self-report measures and example items see Table A.1 of the Supplementary Materials. The demographics section of the survey included items sampling participants' age, gender, and educational level (as indicated by highest achieved or current diploma/degree). Participants were also asked to indicate whether they currently engaged in regular creative activity (whether through study, profession, or hobby).

Schizotypy: The Schizotypal Personality Questionnaire (SPQ; Raine, 1991) was used to quantify schizotypal traits. The SPQ has 74 items constituting nine subscales capturing features of schizotypal personality, modelled on the Diagnostic and Statistical Manual of Mental Disorders (rev. 3rd ed.; DSM-III-R; American Psychiatric Association, 1987) for schizotypal personality disorder. The SPQ captures three symptom dimensions of schizophrenia: positive, negative and disorganised. Positive dimension subscales include: Odd Beliefs/Magical Thinking, Unusual Perceptual Experiences, Ideas of Reference, and Suspiciousness. The SPQ yields high internal reliability and validity (Raine, 1991).

Creative Experience: Most self-report studies to date used creative achievement and/or creative profession to assess creativity when investigating the schizotypy-creativity relationship, with only one study investigating phenomenology of creativity (Nelson \& Rawlings, 2008). Given that the current study population comprised mainly young individuals (students), making it inappropriate to measure creativity by outcomes such as creative achievements or profession, we assessed creative experience using The Experience of Creativity Questionnaire (ECQ; Nelson \& Rawlings, 2009). The ECQ consists of 63 items assessed on a Likert-scale and contains seven factors over two parts: A and B. Part A captures the experience of the creative process: Distinct Experience (i.e., as compared with everyday life), Anxiety, Absorption, Power/Pleasure, Clarity/Preparation. Part B taps into the (existential) meaning of being engaged in creative activity. Only the responses to the items of Part A were included in the current investigation, since they tap into experiential aspects directly related to the creative process, and were found to positively associate with positive schizotypy as measured by O-LIFE (Nelson \& Rawlings, 2010). The ECQ has demonstrated sound construct validity in a sample of 100 artists, but as stated by the authors "the ECQ could potentially be used in studies of creativity with non-artist samples or in studies of other creative domains. For example, a sample not selected for creativity could complete the 
questionnaire by thinking about their most creative experience in any domain or in everyday life." (Nelson \& Rawlings, 2009, p.50).

Dispositional Mindfulness: The Five Facet Mindfulness Questionnaire (FFMQ; Baer et al., 2006) is a 39-item Likert-scale questionnaire measuring five facets: Observing, Acting with Awareness, Describing, Non-Reacting, and Non-Judging. The FFMQ is a widely used measure of dispositional mindfulness with good reliability and validity, with higher scores (indicating higher trait mindfulness) found to associate with better psychological wellbeing (Baer et al., 2006; 2008).

\subsection{Data analysis strategy}

The data were inspected for random response patterns using the analysis of univariate and multivariate outliers, as well as survey response times; no problematic responders were identified.

All variables were checked for distribution normality using Q-Q plots. The scores for the Magical Thinking subscale of the SPQ were positively skewed; consequently, non-parametric approaches were used throughout, including Spearman correlations to investigate relationships between the various scales, and bootstrapping to derive $p$-values and confidence intervals for the main analyses.

To investigate whether the associations between positive schizotypy aspects Magical Thinking and Unusual Experiences with each of the ECQ Part A subscales are attenuated by Suspiciousness (aim i), moderation analysis was performed using 'PROCESS' for SPSS (Hayes, 2013) with 10,000 bootstraps to derive $p$-values corresponding to an alpha level of .01 to adjust for multiple models. Simple slopes analysis was performed to further inspect moderations when Suspiciousness was at low, mean, and high levels (Hayes, 2013). 

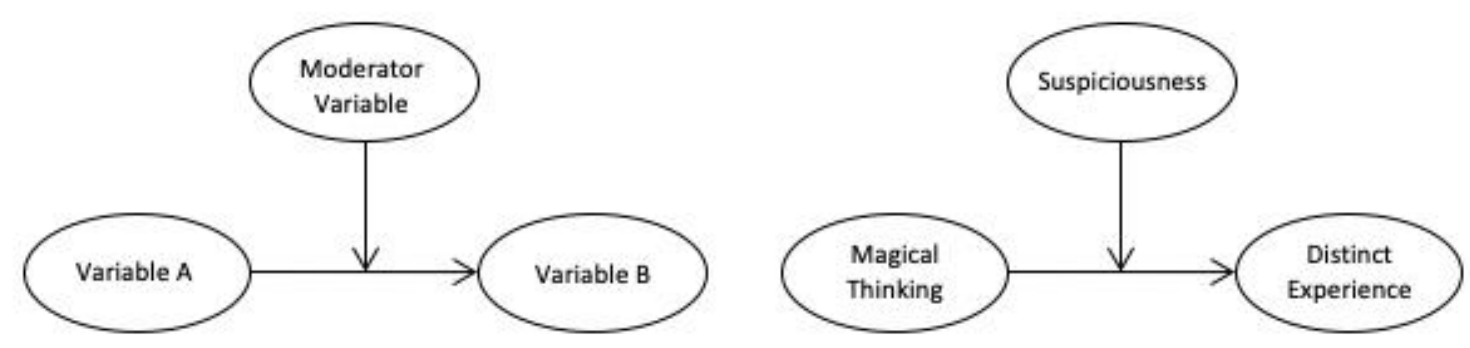

Fig 1. An example of a moderation analysis model testing the moderating effect of SPQ Suspiciousness subscale scores on the relationship between SPQ subscale Magical Thinking and ECQ factor Distinct Experience scores.

To explore whether dispositional mindfulness interacts differentially with the aspects of positive schizotypy (Magical Thinking and Unusual Experiences vs. Suspiciousness and Ideas of Reference) in their relationship with creative experience (aim ii), linear regressions with interaction effects were performed. To decrease the risk of Type I error (given the number of SPQ subscales and FFMQ facets), the number of models was reduced by deriving conglomerate scores for i) Magical Thinking + Unusual Experiences (MTUE) and ii) Suspiciousness + Ideas of Reference (SuspIoR). The subscales were combined into conglomerate scores on the basis of our previous research showing a dissociation between Magical Thinking and Unusual Experiences vs. Suspiciousness and Ideas of Reference in mindfulness meditators (Antonova et al., 2016). Cronbach's alpha for combined items for MTUE and SuspIoR was .77 and .89 , respectively, indicating good reliability of the conglomerate scores. A total of 25 regression models were run to explore interaction effects, with 10,000 bootstraps to derive $p$-values corresponding to the alpha level of .01 to adjust for multiple models.

The regression models were as follows:

$$
Y_{i}=\left(b_{0}+b_{1} A_{i}+b_{2} B_{i}+b_{3} C_{i}+b_{4} A C_{i}+b_{5} \mathrm{BC}_{\mathrm{i}}\right)+e_{i}
$$

Where $\mathrm{A}$ is the score on the first measure, $\mathrm{B}$ is the score on the second measure, $\mathrm{C}$ is the score on the third measure, with $\mathrm{AC}$ and $\mathrm{BC}$ being the interaction terms for the first with the third and the second with the third measures respectively.

For example:

ECQ Absorption $=\left(b_{0}+b_{1} \mathrm{MTUE}_{i}+b_{2} \mathrm{SuspIoR}_{i}+b_{3} \mathrm{FFMQ} \mathrm{Observing}_{i}+b_{4} \mathrm{MTUE} \times\right.$ FFMQ

$$
\text { Observing } \left._{i}+b_{5} \text { SuspIoR x FFMQ Observing }_{i}\right)+ \text { error }_{i}
$$




\section{Results}

\subsection{Sample characteristics}

Sample characteristics can be found in Table 1. Supplementary Materials Table A.1 provides Cronbach's alpha coefficients and Table A.2 provides the mean scores (and standard deviations) of the study's sample for SPQ positive schizotypy, ECQ Part A, and FFMQ subscales.

Table 1. Demographic Sample characteristics.

\begin{tabular}{lc}
\hline Demographic & $\mathbf{N}=\mathbf{3 4 2}$ \\
\hline Age (Mean \pm SD years, range) & $25.97 \pm 8.37,18-61$ \\
\hline & $\boldsymbol{n}(\boldsymbol{\%})$ \\
\hline Gender & \\
Male & $84(24.6)$ \\
Female & $256(74.9)$ \\
Prefer not to say & $2(0.6)$ \\
\hline Education Level & $13(3.8)$ \\
GCSE/Equivalent & $56(16.4)$ \\
College, no degree & $11(3.2)$ \\
Associate degree & $142(41.5)$ \\
Bachelor's degree & $96(28.1)$ \\
Master's degree & $4(1.2)$ \\
Professional degree & $20(5.8)$ \\
Doctorate & $137(40.1)$ \\
\hline Creative Activity Status & $205(59.9)$ \\
Regularly creative* & \\
Not regularly creative/not specified & \\
\hline
\end{tabular}

*Regularly engages in creative activity either as hobby, study, or profession

The mean total SPQ score $(M=20.62, \mathrm{SD}=13.09)$ and SPQ positive schizotypy score $(\mathrm{M}=$ $7.69, \mathrm{SD}=6.21)$ were similar to those observed in general population samples in creativity studies (e.g., Folley \& Park 2005; Gibson et al., 2009). Levels of dispositional mindfulness, whilst marginally higher for Observing, were comparable to meditation-naive general population samples (e.g., Baer et al., 2008, 2011; López et al., 2016). The mean for total FFMQ score was slightly lower than those found in Baer et al.'s (2011) student sample. The sample means for ECQ Part A total and subscale scores (apart from Clarity/Preparation) were slightly lower to those found for the sample of 100 artists (Nelson \& Rawlings, 2009), with the subsample mean of participants regularly engaged in creative activity being more comparable, whereas the subsample for participants without regular engagement was lower. 
Although we defined creativity in broad terms for the purpose of the present study as a process that could be employed in many different contexts, regular engagement in creative activity (e.g. visual art, creative writing, music), either through hobby, profession, or study, was consistently associated with higher scores on all ECQ facets (Table A.5). Further, being regularly engaged in creative activity was associated with higher scores on overall positive schizotypy and its subscales, except for Suspiciousness, with the strongest association being for Magical Thinking (Table A.6). Subsamples with and without regular engagement in creative activities did not differ on overall SPQ scores.

\subsection{Moderation analysis}

Magical Thinking, Unusual Experiences, and Suspiciousness subscales of the $S P Q$ significantly positively correlated with the scores on ECQ facets related to positive 'flow'type experience of creativity, namely Distinct Experience, Absorption, and Power/Pleasure (See Table A.2; Fig. A.1a).

Suspiciousness attenuated the positive associations of Magical Thinking and Unusual Experiences with Power/Pleasure (see Table 2 for the results of the moderation analysis). The attenuating effect of Suspiciousness upon the relationship between Unusual Experiences and Power/Pleasure was highly significant (interaction effect: $b=-.23,95 \%$ CI [-.42, -.05], $p$ $=.01$ ), whereas it was significant at the unadjusted alpha level of .05 for the relationship between Magical Thinking and Power/Pleasure (interaction effect: $b=-.29,95 \%$ CI [-.54, .03], $p=.03$ ). Simple slopes analysis indicated that when Suspiciousness scores were low-to mean, there was a significant positive linear relationship between Unusual Experiences and Magical Thinking with Power/Pleasure scores $(p<.001)$; however, this relationship was disrupted (and completely non-significant for Unusual Experiences) when Suspiciousness scores were higher than mean (see Table 2 and Fig. 2). ${ }^{1}$

\footnotetext{
${ }^{1}$ Post-hoc power analysis revealed that for our main hypothesis (moderation analysis), with the sample size of 342 and 3-predictor variable equations, the power for the detection of small-to-medium effect sizes obtained at the adjusted .01 level is .99 (Cohen, 1988; calculated using G*Power, Erdfelder, Faul, \& Buchner, 1996).
}

No further significant moderations were observed (see Table A.3 for full results). 
Table 2. Significant moderations and conditional effects of Suspiciousness on the relationship of SPQ Magical Thinking and Unusual Perceptual Experiences with ECQ Power/Pleasure.

\begin{tabular}{|c|c|c|c|}
\hline & Model & $\beta(S E)$ & $p$ value $[95 \% \mathrm{CI}]$ \\
\hline \multirow[t]{9}{*}{ Magical Thinking } & \multicolumn{3}{|l|}{ Predictor } \\
\hline & MT & $1.52(.29)$ & $<.001[.96,2.08]$ \\
\hline & Susp & $.50(.20)$ & $.02[.10, .90]$ \\
\hline & MT x Susp & $-.29(.13)$ & $.03[-.54,-.03]$ \\
\hline & \multicolumn{3}{|c|}{ Model Summary $R^{2}=.11, F(3,338)=13.91, p<.001 ; f^{2}=.12$} \\
\hline & \multicolumn{3}{|c|}{ Conditional Effects of Suspiciousness } \\
\hline & - $1 S D$ below Mean & $2.16(.43)$ & $<.001[1.32,3.01]$ \\
\hline & Mean & $1.52(.28)$ & $<.001[.96,2.08]$ \\
\hline & $+1 S D$ Above Mean & $.89(.39)$ & $.02[.15,1.62]$ \\
\hline \multirow[t]{8}{*}{$\begin{array}{l}\text { Unusual Perceptual } \\
\text { Experiences }\end{array}$} & Unex & $.80(.23)$ & $<.001[.34,1.25]$ \\
\hline & Susp & $.55(.23)$ & $.02[.10,1.00]$ \\
\hline & UnEx x Susp & $-.23(.09)$ & $.01[-.42,-.05]$ \\
\hline & \multicolumn{3}{|c|}{ Model Summary $R^{2}=.08, F(3,338)=9.22, p<.001 ; f^{2}=.09$} \\
\hline & \multicolumn{3}{|c|}{ Conditional Effects of Suspiciousness } \\
\hline & - $1 S D$ below Mean & $1.32(.34)$ & $<.001[.64,1.99]$ \\
\hline & Mean & $.80(.23)$ & $<.001[.34,1.25]$ \\
\hline & + $1 S D$ Above Mean & $.27(.28)$ & $.33[-.28 . .92]$ \\
\hline
\end{tabular}

Abbreviations: $\mathrm{MT}=$ Magical Thinking; Susp = Suspiciousness $;$ UnEx = Unusual Perceptual Experiences.

a)

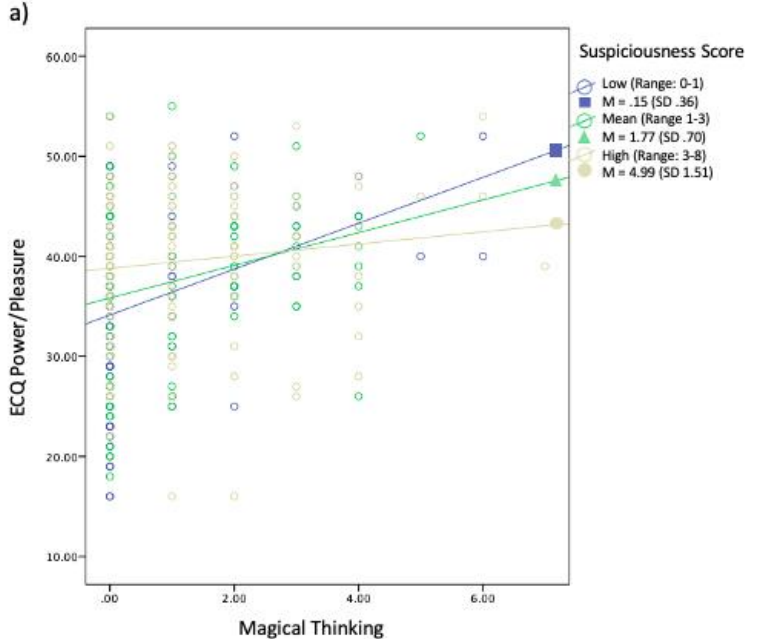

b)

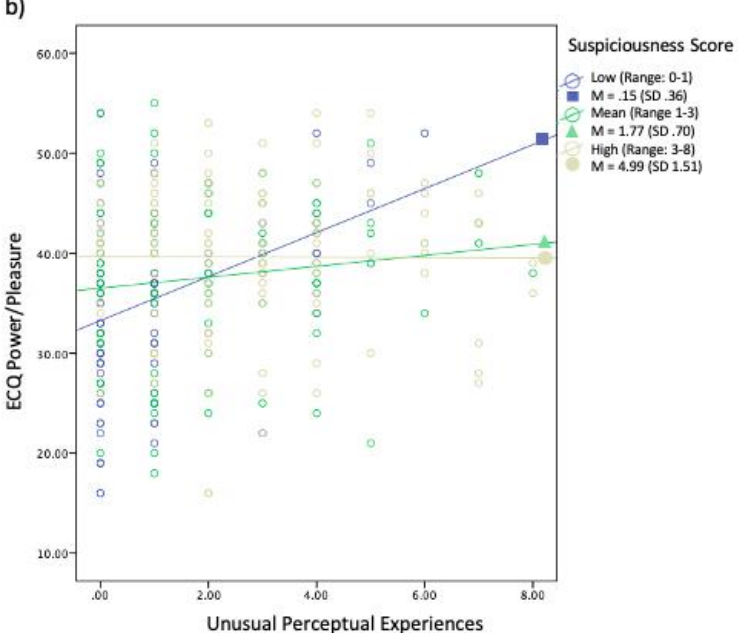

Fig. 2. Scatter plots of the raw data demonstrating the relationship between: a) SPQ Magical Thinking and ECQ Power/Pleasure, and b) SPQ Unusual Perceptual Experiences and ECQ Power/Pleasure for the sub-groups with low, mean, and high Suspiciousness scores. 


\subsection{Interaction effect analysis}

There were a number of significant correlations between SPQ, FFMQ, and ECQ subscales (see Table A.2 and Fig. A.1). Higher total FFMQ and FFMQ subscale scores, except for Observing, significantly correlated with lower scores on SPQ Suspiciousness. Associations between FFMQ facets and ECQ Part A subscales were somewhat mixed, with positive correlations between FFMQ Observing and most ECQ subscales, and negative associations between most FFMQ facets and ECQ Anxiety (see Table A.2, and Fig. A.1). Suspiciousness and Ideas of Reference of the SPQ showed similar pattern of associations with the FFMQ subscales, whereas Magical Thinking and Unusual Experiences behaved similarly to each other, providing further justification for using conglomerate scores for Magical Thinking and Unusual Experiences (MTUE) and Suspiciousness and Ideas of Reference (SuspIoR) in exploring the interactions between positive schizotypy and dispositional mindfulness in relation to experience of creativity.

Table 3 presents a summary of the significant interaction effects (see Fig. A.2, and Table A.4 for the full results of linear regression analyses). FFMQ Acting with Awareness significantly interacted with MTUE in predicting Clarity/Preparation ( $b=.03, p=.004)$, such that higher levels of Acting with Awareness increased the positive association between MTUE and Clarity/Preparation scores. FFMQ Non-Reacting significantly interacted with MTUE in predicting ECQ Anxiety ( $b=-.06, p=.003)$, such that as Non-Reacting scores increased, the positive association between MTUE and Anxiety decreased. Higher levels of Describing strengthened the positive association between MTUE and Power/Pleasure, with the interaction effect being significant at the unadjusted alpha level $(b=.06, p=.03)$. A significant interaction between FFMQ Describing and SuspIoR indicated that as Describe scores increased, the stronger the positive association between SuspIoR and Anxiety scores became $(b=.03, p=.047)$. 
Table 3. The results of multiple linear regression analysis with significant interactions between FFMQ facet scores and conglomerate scores for SPQ Magical Thinking + Unusual Experiences vs. Suspiciousness + Ideas of Reference on predicting ECQ factor scores.

\begin{tabular}{|c|c|c|c|c|c|c|c|c|c|c|c|}
\hline \multicolumn{12}{|c|}{ ECQ Factor } \\
\hline & & \multicolumn{2}{|c|}{ Distinct Experience } & \multicolumn{2}{|c|}{ Anxiety } & \multicolumn{2}{|c|}{ Absorption } & \multicolumn{2}{|c|}{ Power/Pleasure } & \multicolumn{2}{|c|}{ Clarity/Preparation } \\
\hline \multirow{7}{*}{$\begin{array}{l}\text { FFMQ Facet } \\
\text { Describing }\end{array}$} & Predictor Variable & $\beta(\mathrm{SE})$ & $95 \% \mathrm{CI}$ & $\beta(\mathrm{SE})$ & $95 \% \mathrm{CI}$ & $\beta(\mathrm{SE})$ & $95 \% \mathrm{CI}$ & $\beta(\mathrm{SE})$ & $95 \% \mathrm{CI}$ & $\beta(\mathrm{SE})$ & $95 \% \mathrm{CI}$ \\
\hline & MTUE & & - & $.37 * *(.120)$ & {$[.12, .60]$} & & - & $.48 * *(.16)$ & {$[.18, .79]$} & & \\
\hline & SuspIoR & & - & $.29 * *(.09)$ & {$[-.13,-.46]$} & & - & $.42 * *(.11)$ & {$[.20, .64]$} & & \\
\hline & Desc & & - & $-.11 *(.06)$ & {$[-.22,-.01]$} & & - & $.12(.07)$ & {$[-.03, .26]$} & & \\
\hline & MTUE $\times$ Desc & & - & $-.02(.02)$ & {$[-.06, .02]$} & & - & $.06^{*}(.03)$ & {$[.00, .12]$} & & \\
\hline & SuspIoR x Desc & & - & $.03 *(.01)$ & {$[.00, .06]$} & & - & $-.01(.02)$ & {$[-.05, .03]$} & & \\
\hline & Model Summary & & - & $\begin{array}{r}\text { Adjustec } \\
F(5,336)=\end{array}$ & $\begin{array}{l}R^{2}=.14 \\
.82, p<.001\end{array}$ & & - & $\begin{array}{r}\text { Adjuste } \\
F(5,336)=\end{array}$ & $\begin{array}{l}R^{2}=.11 \\
.41, p<.001\end{array}$ & & \\
\hline \multirow{6}{*}{$\begin{array}{l}\text { Non-Reacting } \\
\text { (NR) }\end{array}$} & MTUE & & - & $.37 * *(.12)$ & {$[.13, .61]$} & & - & & & & \\
\hline & SuspIoR & & - & $.36 * *(.08)$ & {$[.16,48]$} & & - & & & & \\
\hline & $N R$ & & - & $-.02(.07)$ & {$[-.15, .11]$} & & - & & & & \\
\hline & MTUE $\times N R$ & & - & $-.06 * *(.02)$ & {$[-.11,-.02]$} & & - & & & & \\
\hline & SuspIoR $x N R$ & & - & $.03(.01)$ & {$[-.01, .06]$} & & - & & & & \\
\hline & Model Summary & & - & $\begin{array}{r}\text { Adjustec } \\
F(5,336)=\end{array}$ & $\begin{array}{l}R^{2}=.13, \\
.19, p<.001\end{array}$ & & - & & & & \\
\hline \multirow{6}{*}{$\begin{array}{l}\text { Acting with } \\
\text { Awareness }(A w A)\end{array}$} & MTUE & & - & & & & - & & & $.22 * *(.07)$ & {$[.09, .35]$} \\
\hline & SuspIoR & & - & & & & - & & & $.07(.05)$ & {$[-.02, .17]$} \\
\hline & $A w A$ & & - & & & & - & & & $.06(.03)$ & {$[-.01, .11]$} \\
\hline & MTUE $x A w A$ & & - & & & & - & & & $.03 * *(.01)$ & {$[.01, .05]$} \\
\hline & SuspIoR $x A w A$ & & - & & & & - & & & $-.01(.01)$ & {$[-.02, .01]$} \\
\hline & Model Summary & & - & & & & - & & & $\begin{array}{r}\text { Adjuste } \\
F(5,336)\end{array}$ & $\begin{array}{l}l^{2}=.06 \\
p<.001\end{array}$ \\
\hline
\end{tabular}

$* p<.05, * * p<.01$

Abbreviations: AwA = Acting with Awareness; Desc = Describing; ECQ = Experience of Creativity Questionnaire $;$ FFMQ = Five Facet Mindfulness

Questionnaire; MTUE = Magical Thinking + Unusual Experiences conglomerate scores; NR = Non-Reacting; SuspIoR = Suspiciousness + Ideas of Reference conglomerate scores. 


\section{Discussion}

The study aimed to investigate the inter-relationships between positive schizotypy, dispositional mindfulness, and experience of creativity. In partial support of our hypothesis, the positive linear relationship between the positive schizotypy aspects of magical thinking and unusual experiences with the experience of creativity was attenuated by higher levels of suspiciousness/paranoia. However, this effect was specific to the aspect of Power/Pleasure, and was significant at the unadjusted alpha level of .05 for Magical Thinking. No moderation effects were observed for Distinct Experience, Absorption, Anxiety, or Clarity/Preparation. Explorative analysis showed the interactive effects of dispositional mindfulness upon the relationship between the aspects of positive schizotypy and creative experience.

\subsection{Moderation of the relationship between positive schizotypy and creative experience by suspiciousness}

Suspiciousness/paranoia attenuated the positive relationship of magical thinking and unusual experiences with the power/pleasure aspect of creative experience. However, higher level of suspiciousness in itself was associated with higher power/pleasure. Nevertheless, when higher levels of magical thinking or unusual experiences were accompanied by low-to-mean suspiciousness levels, the self-reported power/pleasure was higher than when they were accompanied by higher levels of suspiciousness (see Fig. 2).

This pattern of the results may explain the inconsistency observed in the previous studies using the SPQ to investigate the relationship between positive schizotypy and creativity (for example, Minor et al., 2014 found a significant positive relationship, but Fink et al., 2013; Gibson et al., 2009; Rominger et al., 2014 did not). The findings using the O-LIFE, which captures magical thinking and unusual experiences but not suspiciousness, have been more consistent, with many studies having observed positive relationships between positive schizotypy and creativity (e.g., Batey \& Furnham, 2008; Nettle \& Clegg, 2006; Rawlings \& Locarnani, 2008; Winston et al., 2014; but see Claridge \& McDonald, 2009; Rybakowski \& Klonowska 2011). Our findings suggest that the inconsistency between studies using different self-report measures may arise due to the quantification of positive schizotypy with or without suspiciousness as one of its aspects. Conversely, inconsistencies between the studies using the same self-report measure could be due to the samples being different on the levels of suspiciousness/paranoia; something that would be missed if suspiciousness is not assessed at all, or if only the total positive schizotypy score of the SPQ is used in probing the 
relationship with creativity. Future studies should give special consideration to the role of suspiciousness when investigating the relationship between positive schizotypy and creativity. The studies using O-LIFE should additionally quantify suspiciousness/paranoia; for example, by utilising the recommended Paranoia/Suspiciousness Questionnaire (PSQ; Rawlings and Freeman, 1997), whereas the studies using the SPQ should pay attention to the 'composition' of high positive schizotypy by the scores on different subscales (e.g. high magical thinking and/or unusual experiences vs. suspiciousness/paranoia).

The observed attenuating effect of suspiciousness/paranoia was specific to the experience of power/pleasure, even though magical thinking and unusual experiences (as well as suspiciousness) were significantly positively correlated with other 'flow'- type aspects of creative experience as measured by Distinct Experience and Absorption ECQ sub-scales. The Power/Pleasure subscale taps into a positive affect experienced during a 'flow'-like state associated with being emerged in a creative activity (pleasure), as well as a sense of control (power) (Csikszentmihalyi, 1990; Nelson and Rawlings, 2009). Pleasure is a defining feature of 'flow' (Nelson \& Rawlings, 2009) and a key part of the creative process (Henderson, 2004; Russ, 1993) that contributes to intrinsic motivation for creative activity (Nelson \& Rawlings, 2007), aiding creative output (Amabile et al., 1985; Amabile et al., 1996). The specificity of the observed attenuating moderation upon power/pleasure as an aspect of creative experience should be investigated further, alongside understanding the interaction of magical thinking and/or unusual experiences with suspiciousness in relation to the type of creative activity and output.

\subsection{Inter-relationships between positive schizotypy, dispositional mindfulness, and creative experience}

When exploring the interaction effects between dispositional mindfulness and conglomerate scores on Magical Thinking/Unusual Experiences vs. Suspiciousness/Ideas of Reference on predicting ECQ subscale scores, mindfulness facets Describing, Non-Reacting, and Acting with Awareness were found to affect the relationship between the aspects of positive schizotypy and creative experience as captured by ECQ subscales Power/Pleasure, Anxiety, and Clarity/Preparation.

Specifically, Describing strengthened the predictive power of Magical Thinking/Unusual Experience upon Power/Pleasure. However, Describing also enhanced the predictive power 
of Suspiciousness/Ideas of Reference upon Anxiety. The items constituting ECQ's Anxiety subscale mainly refer to the state of fragility, vulnerability, and exhaustion following the creative activity, but some items refer to the creative process itself as being fragile due to absorption being interrupted by becoming self-conscious. Suspiciousness/paranoia and ideas of reference as instances of self-referential processing might 'colour' the ability to describe experiences through self-critical lens, increasing the sense of instability of the 'flow' state. Given the enhancing effect of Describing on the relationship between Magical Thinking/Unusual Experiences and Power/Pleasure, mindfulness training to reduce suspiciousness may remove the double-edge sword of the ability to describe experiences by reducing critical self-referencing and the activity of the associated Default Mode Network $(\mathrm{DMN})$ - the main mechanism underlying the efficacy of mindfulness-based interventions (e.g. Berkovich-Ohana et al., 2012; Brewer et al., 2011; Farb et al. 2007; Goldin et al., 2009).

The potential positive effect of mindfulness training on creative experience in people with positive schizotypy is further indicated by the finding that Non-Reacting weakened the positive association between Magical Thinking/Unusual Experience and Anxiety. NonReacting, an ability to be present with one's experiences, whether pleasant or unpleasant, without reacting to or being caught up in them, might buffer against anxiety/vulnerabilityprovoking experience during and after creative process. Non-reactivity as one of the last mindfulness skills to emerge as a result of mindfulness training using Mindfulness-Based Cognitive Therapy (Kuyken et al., 2010), and was found to differentiate meditators from nonmeditators (Antonova et al., 2016; Soler et al., 2014), adding impetus for using mindfulnessbased interventions for developing non-reactivity towards the aspects of creative process that might be experienced as negative/unpleasant.

Acting with Awareness enhanced the predictive power of Magical Thinking/Unusual Experience upon Clarity/Preparation. Acting with Awareness facet is mainly comprised of the items pertaining to the Mindful Attention and Awareness Scale (Brown and Ryan, 2003), measuring the propensity to run on 'automatic pilot'/mind-wander during daily activities, so its association with being clear and aware of one's actions before and during creative engagement is intuitively appealing. Acting with awareness predicts cognitive flexibility and control (Moore \& Malinowski, 2009), known to aid creativity (Zabelina \& Robinson, 2010). In addition to the interactions, dispositional mindfulness, except for the facet Observing, significantly correlated with lower suspiciousness, complimenting previous findings 
(Antonova et al., 2016; Kingston et al., 2019). Mindfulness promotes inter-personal attitudes (Condon, 2017) incompatible with suspiciousness/paranoia (Freeman et al., 2005), increasing metacognitive insight and decentred awareness (Chadwick, 2006), which may reduce reactivity to and fixation upon suspicious/paranoid thoughts. Greater dispositional mindfulness also negatively correlated with ideas of reference, in line with the results of Antonova et al. (2016), a trait linked to both paranoia (Bebbington et al., 2013; Fenigstein \& Vanable, 1992) and over-active DMN in schizophrenia, associated with hyper selfreferencing (Cannon, 2015; Whitfield-Gabrieli et al., 2009).

Previous research points to a genetic overlap between creativity and schizophrenia and related disorders, with polygenic risk scores for these disorders being shown to significantly associate with creativity ( $\mathrm{Li}$ et al., 2020; Power et al., 2015). Our findings provide further support for the notion that schizophrenia-related genotype/phenotype may afford evolutionary benefits such as creative ability, particularly in milder expressions of its features (Kinney et al., 2001, Acar et al., 2018) such as positive schizotypy (Acar \& Sen, 2013), which might explain its presence in the general population. On the other hand, suspiciousness/paranoia, an aspect of positive schizotypy, carries high predictive power for conversion to psychosis in high-risk individuals (Cannon et al., 2008). The findings of the current study suggest that it has an attenuating effect of positive association of magical thinking and unusual experiences with the aspects of creative experience related to positive affect. Given that higher dispositional mindfulness was also associated with lower suspiciousness, together, our findings provide support for the use of mindfulness-based interventions in protecting against psychosis risk presented by suspicious/paranoia, whilst preserving and possibly enhancing an otherwise favourable association of magical thinking and unusual experiences with the creative process.

\subsection{Study limitations}

The present study was primarily concerned with moderation and interaction effects, rather than prediction models of 'best fit'; however, we note the relatively small effect sizes observed for the models. This may indicate noise due to measurement error (Loken \& Gelman, 2017), with ECQ sub-facet 'Clarity/Preparation' having poor reliability in the present sample (Cronbach alpha of .53, see Table A.1). More generally, the ECQ's validity and internal consistency is yet to be established. However, it is reassuring that we have replicated the findings using the SPQ to those reported by Nelson and Rawlings (2010) using 
O-LIFE. Furthermore, reassuringly higher scores on all facets of creative experience were associated with being regularly engaged with creative activity in the present sample, aiding ECQ's construct validity.

The use of self-report mindfulness measures in the general population has been criticized due to the possibility of the items being misinterpreted by meditation-naïve individuals (Grossman, 2008). However, the observed interactive effects fit well within the theoretical framework used in this study. They do, nevertheless, require a replication due to the large number of tests performed, with some associations observed at the unadjusted alpha level.

\section{Conclusions}

The study provides preliminary evidence that higher levels of suspiciousness/paranoia disrupt the positive relationship of magical thinking and unusual experiences with creative experience, which might help to explain the inconsistency of previous research into the link between positive schizotypy and creativity. The explorative findings suggest that dispositional mindfulness enhances the associations of magical thinking and unusual experiences with the aspects of creative experience related to positive affect and clarity/preparation. An overall pattern of the results, including the inverse relationship between most aspects of dispositional mindfulness and suspiciousness/paranoia, warrants the application of mindfulness-based interventions for reducing suspiciousness/paranoia as psychosis risk factor, whilst supporting the otherwise favourable association of magical thinking and unusual experiences with creativity. 


\section{References}

Acar, S., Chen, X., \& Cayirdag, N. (2018). Schizophrenia and creativity: A meta-analytic review. Schizophrenia research, 195, 23-31. https://doi.org/10.1016/j.schres.2017.08.036

Acar, S., \& Sen, S. (2013). A multilevel meta-analysis of the relationship between creativity and schizotypy. Psychology of Aesthetics, Creativity, and the Arts, 7(3), 214. https://doi.org/10.1037/a0031975.

Amabile, T. M. (1985). Motivation and creativity: Effects of motivational orientation on creative writers. Journal of Personality and Social Psychology, 48(2), 393. https://doi.org/10.1037/0022-3514.48.2.393.

Amabile, T. M., Conti, R., Coon, H., Lazenby, J., \& Herron, M. (1996). Assessing the work environment for creativity. Academy of Management Journal, 39(5), 1154-1184. https://doi.org/10.5465/256995.

Antonova, E., Amaratunga, K., Wright, B., Ettinger, U., \& Kumari, V. (2016). Schizotypy and mindfulness: Magical thinking without suspiciousness characterizes mindfulness meditators. Schizophrenia Research: Cognition, 5, 1-6. https://doi.org/10.1016/j.scog.2016.05.001.

Antonova, E., Chadwick, P., \& Kumari, V. (2015). More meditation, less habituation? The effect of mindfulness practice on the acoustic startle reflex. PloS One, 10(5). https://doi.org/10.1371/journal.pone.0133099.

Baer, R. A., Samuel, D. B., \& Lykins, E. L. (2011). Differential item functioning on the Five Facet Mindfulness Questionnaire is minimal in demographically matched meditators and nonmeditators. Assessment, 18(1), 3-10. https://doi.org/10.1177/1073191110392498.

Baer, R. A., Smith, G. T., Hopkins, J., Krietemeyer, J., \& Toney, L. (2006). Using self-report assessment methods to explore facets of mindfulness. Assessment, 13(1), 27-45. https://doi.org/10.1177/1073191105283504.

Baer, R. A., Smith, G. T., Lykins, E., Button, D., Krietemeyer, J., Sauer, S., \& Williams, J. M. G. (2008). Construct validity of the five facet mindfulness questionnaire in meditating and nonmeditating samples. Assessment, 15(3), 329-342. https://doi.org/10.1177/1073191107313003.

Batey, M., \& Furnham, A. (2008). The relationship between measures of creativity and schizotypy. Personality and Individual Differences, 45(8), 816-821. https://doi.org/10.1016/j.paid.2008.08.014.

Bebbington, P. E., McBride, O., Steel, C., Kuipers, E., Radovanoviĉ, M., Brugha, T., Jenkins, R., Meltzer, H. I., \& Freeman, D. (2013). The structure of paranoia in the general population. The British Journal of Psychiatry, 202(6), 419-427. https://doi.org/10.1192/bjp.bp.112.119032.

Berkovich-Ohana, A., Glicksohn, J., \& Goldstein, A. (2012). Mindfulness-induced changes in gamma band activity-implications for the default mode network, self-reference and 
attention. Clinical Neurophysiology, 123(4), 700-710.

https://doi.org/10.1016/j.clinph.2011.07.048.

Bishop, S. R., Lau, M., Shapiro, S., Carlson, L., Anderson, N. D., Carmody, J., \& Devins, G. (2004). Mindfulness: A proposed operational definition. Clinical psychology: Science and practice, 11(3), 230-241. https://doi.org/10.1093/clipsy.bph077.

Brewer, J. A., Worhunsky, P. D., Gray, J. R., Tang, Y.-Y., Weber, J., \& Kober, H. (2011). Meditation experience is associated with differences in default mode network activity and connectivity. Proceedings of the National Academy of Sciences, 108(50), 20254 20259. https://doi.org/10.1073/pnas.1112029108.

Brown, K. W., \& Ryan, R. M. (2003). The benefits of being present: mindfulness and its role in psychological well-being. Journal of Personality and Social Psychology, 84(4), 822. https://doi.org/10.1037/0022-3514.84.4.822.

Cannon, T. D. (2015). How Schizophrenia Develops: Cognitive and Brain Mechanisms Underlying Onset of Psychosis. Trends in Cognitive Sciences, 19(12), 744-756. https://doi.org/10.1016/j.tics.2015.09.009.

Cannon, T. D., Cadenhead, K., Cornblatt, B., Woods, S. W., Addington, J., Walker, E., Seidman, L. J., Perkins, D., Tsuang, M., \& McGlashan, T. (2008). Prediction of psychosis in youth at high clinical risk: a multisite longitudinal study in North America. Archives of General Psychiatry, 65(1), 28-37.

https://doi.org/10.1001/archgenpsychiatry.2007.3.

Chadwick, P. (2006). Person-based cognitive therapy for distressing psychosis. Chichester, UK: Wiley. https://doi.org/10.1002/9780470713075.

Claridge, G., \& McDonald, A. (2009). An investigation into the relationships between convergent and divergent thinking, schizotypy, and autistic traits. Personality and Individual Differences, 46(8), 794-799. https://doi.org/10.1016/b978-0-12-3750389.00021-2.

Cohen, J. (1988). Statistical power analysis for the behavioral sciences (2nd ed.). Hillsdale, NJ: Erlbaum.

Condon, P. (2017). Mindfulness, compassion, and prosocial behavior. In J. C. Karremans \& E. K. Papies (Eds.), Mindfulness in social psychology. Hove, UK: Psychology Press.

Csikszentmihalyi, M. (1990) Flow: The Psychology of Optimal Experience. New York: Harper Perennial.

Debbané, M., Eliez, S., Badoud, D., Conus, P., Flückiger, R., \& Schultze-Lutter, F. (2015). Developing Psychosis and Its Risk States Through the Lens of Schizotypy. Schizophrenia Bulletin, 41(2), S396-S407. https://doi.org/10.1093/schbul/sbu176.

Erdfelder, E., Faul, F., \& Buchner, A. (1996). GPOWER: A general power analysis program. Behavior research methods, instruments, \& computers, 28(1), 1-11. https://doi.org/10.3758/BF03203630 
Ettinger, U., Meyhofer, I., Steffens, M., Wagner, M., \& Koutsouleris, N. (2014). Genetics, cognition, and neurobiology of schizotypal personality: a review of the overlap with schizophrenia. Frontiers in Psychiatry, 5(18). https://doi.org/10.3389/fpsyt.2014.00018.

Farb, N. A. S., Segal, Z. V, Mayberg, H., Bean, J., McKeon, D., Fatima, Z., \& Anderson, A. K. (2007). Attending to the present: mindfulness meditation reveals distinct neural modes of self-reference. Social Cognitive and Affective Neuroscience, 2(4), 313-322. https://doi.org/10.1093/scan/nsm030.

Fenigstein, A., \& Vanable, P. A. (1992). Paranoia and self-consciousness. Journal of Personality and Social Psychology, 62(1), 129. https://doi.org/10.1037/00223514.62.1.129.

Fink, A., Weber, B., Koschutnig, K., Benedek, M., Reishofer, G., Ebner, F., Papousek, I., \& Weiss, E. M. (2014). Creativity and schizotypy from the neuroscience perspective. Cognitive, Affective, \& Behavioral Neuroscience, 14(1), 378-387. https://doi.org/10.3758/s13415-013-0210-6.

Folley, B. S., \& Park, S. (2005). Verbal creativity and schizotypal personality in relation to prefrontal hemispheric laterality: A behavioral and near-infrared optical imaging study. Schizophrenia Research, 80(2-3), 271-282. https://doi.org/10.1016/j.schres.2005.06.016.

Freeman, D., Garety, P. A., Bebbington, P. E., Smith, B., Rollinson, R., Fowler, D., Kuipers, E., Ray, K., \& Dunn, G. (2005). Psychological investigation of the structure of paranoia in a non-clinical population. The British Journal of Psychiatry, 186(5), 427-435. https://doi.org/10.1192/bjp.186.5.427.

Freeman, D., Pugh, K., Antley, A., Slater, M., Bebbington, P., Gittins, M., Dunn, G., Kuipers, E., Fowler, D., \& Garety, P. (2008). Virtual reality study of paranoid thinking in the general population. The British Journal of Psychiatry, 192(4), 258-263. https://doi.org/10.1192/bjp.bp.107.044677.

Gibson, C., Folley, B. S., \& Park, S. (2009). Enhanced divergent thinking and creativity in musicians: A behavioral and near-infrared spectroscopy study. Brain and Cognition, 69(1), 162-169. https://doi.org/10.1016/j.bandc.2008.07.009.

Goldin, P., Ramel, W., \& Gross, J. (2009). Mindfulness meditation training and selfreferential processing in social anxiety disorder: Behavioral and neural effects. Journal of Cognitive Psychotherapy, 23(3), 242-257. https://doi.org/10.1891/08898391.23.3.242.

Grossman, P. (2008). On measuring mindfulness in psychosomatic and psychological research. Journal of Psychosomatic Research, 4(64), 405-408. https://doi.org/10.1016/j.jpsychores.2008.02.001.

Hayes, A. F. (2013). Introduction to mediation, moderation, and conditional process analysis: A regression-based approach. New York: Guilford Publications. https://doi.org/10.1111/jedm.12050. 
Henderson, S. J. (2004). Product inventors and creativity: The finer dimensions of enjoyment. Creativity Research Journal, 16(2-3), 293-312.

https://doi.org/10.1080/10400419.2004.9651460.

Kingston, J., Lassman, F., Matias, C., \& Ellett, L. (2019). Mindfulness and Paranoia: A Cross-Sectional, Longitudinal and Experimental Analysis. Mindfulness, 10(10), 20382045. https://doi.org/10.1007/s12671-019-01162-2.

Kinney, D. K., Richards, R., Lowing, P. A., LeBlanc, D., Zimbalist, M. E., \& Harlan, P. (2001). Creativity in offspring of schizophrenic and control parents: An adoption study. Creativity Research Journal, 13(1), 17-25. https://doi.org/10.1207/S15326934CRJ1301_3

Kuyken, W., Watkins, E., Holden, E., White, K., Taylor, R. S., Byford, S., \& Dalgleish, T. (2010). How does mindfulness-based cognitive therapy work? Behaviour Research and Therapy, 48(11), 1105-1112. https://doi.org/10.1016/j.brat.2010.08.003.

Kwapil, T. R., Gross, G. M., Silvia, P. J., \& Barrantes-Vidal, N. (2013). Prediction of psychopathology and functional impairment by positive and negative schizotypy in the Chapmans' ten-year longitudinal study. Journal of Abnormal Psychology, 122(3), 807. https://doi.org/10.1037/a0033759.

Kwapil, T. R., Kemp, K. C., Mielock, A., Sperry, S. H., Chun, C. A., Gross, G. M., \& Barrantes-Vidal, N. (2020). Association of multidimensional schizotypy with psychoticlike experiences, affect, and social functioning in daily life: Comparable findings across samples and schizotypy measures. Journal of Abnormal Psychology. https://dx.doi.org/10.1037/abn0000522.

Lenzenweger, M. F. (2015). Thinking Clearly About Schizotypy: Hewing to the Schizophrenia Liability Core, Considering Interesting Tangents, and Avoiding Conceptual Quicksand. Schizophrenia Bulletin, 41(2), S483-S491. https://doi.org/10.1093/schbul/sbu184.

Li, H., Zhang, C., Cai, X., Wang, L., Luo, F., Ma, Y., \& Xiao, X. (2020). Genome-wide association study of creativity reveals genetic overlap with psychiatric disorders, risk tolerance, and risky behaviors. Schizophrenia Bulletin. https://doi.org/10.1093/schbul/sbaa025

Loken, E., \& Gelman, A. (2017). Measurement error and the replication crisis. Science, 355(6325), 584-585. https://doi.org/10.1126/science.aal3618.

López, A., Sanderman, R., \& Schroevers, M. J. (2016). Mindfulness and self-compassion as unique and common predictors of affect in the general population. Mindfulness, 7(6), 1289-1296. https://doi.org/10.1007/s12671-016-0568-y.

Mason, O., Claridge, G., \& Jackson, M. (1995). New scales for the assessment of schizotypy. Personality and Individual differences, 18(1), 7-13. https://doi.org/10.1016/01918869(94)00132-C. 
Mason, O., Claridge, G., Williams, L., 1997. Questionnaire measurement. In: Claridge, G. (Ed.), Schizotypy: Implications for Illness and Health. (pp. 19-37). Oxford University Press, Oxford, England. https://doi.org/10.1093/med:psych/9780198523536.003.0002.

Michalica, K., \& Hunt, H. (2013). Creativity, schizotypicality, and mystical experience: An empirical study. Creativity Research Journal, 25(3), 266-279. https://doi.org/10.1080/10400419.2013.813780.

Moore, A., \& Malinowski, P. (2009). Meditation, mindfulness and cognitive flexibility. Consciousness and cognition, 18(1), 176-186. https://doi.org/10.1016/j.concog.2008.12.008.

Nelson, B., \& Rawlings, D. (2007). Its Own Reward: A Phenomenological Study of Artistic Creativity. Journal of Phenomenological Psychology, 38, 217-255. https://doi.org/10.1163/156916207x234284.

Nelson, B., \& Rawlings, D. (2010). Relating schizotypy and personality to the phenomenology of creativity. Schizophrenia Bulletin, 36(2), 388-399. https://doi.org/10.1093/schbul/sbn098.

Nelson, B., \& Rawlings, D. (2009). How does it feel? The development of the experience of creativity questionnaire. Creativity Research Journal, 21(1), 43-53. https://doi.org/10.1080/10400410802633442.

Nelson, M. T., Seal, M. L., Pantelis, C., \& Phillips, L. J. (2013). Evidence of a dimensional relationship between schizotypy and schizophrenia: a systematic review. Neuroscience \& Biobehavioral Reviews, 37(3), 317-327. https://doi.org/10.1016/j.neubiorev.2013.01.004.

Nettle, D., \& Clegg, H. (2006). Schizotypy, creativity and mating success in humans. Proceedings of the Royal Society B: Biological Sciences, 273(1586), 611-615. https://doi.org/10.1098/rspb.2005.3349.

Nijstad, B. A., De Dreu, C. K. W., Rietzschel, E. F., \& Baas, M. (2010). The dual pathway to creativity model: Creative ideation as a function of flexibility and persistence. European Review of Social Psychology, 21(1), 34-77. https://doi.org/10.1080/10463281003765323.

Polner, B., Nagy, H., Takáts, A., \& Kéri, S. (2015). Kiss of the muse for the chosen ones: De novo schizotypal traits and lifetime creative achievement are related to changes in divergent thinking during dopaminergic therapy in Parkinson's disease. Psychology of Aesthetics, Creativity, and the Arts, 9(3), 328. https://doi.org/10.1037/a0039303.

Power, R. A., Steinberg, S., Bjornsdottir, G., Rietveld, C. A., Abdellaoui, A., Nivard, M. M., $\&$ Cesarini, D. (2015). Polygenic risk scores for schizophrenia and bipolar disorder predict creativity. Nature neuroscience, 18(7), 953-955. https://doi.org/10.1038/nn.4040 
Raine, A. (1991). The SPQ: a scale for the assessment of schizotypal personality based on DSM-III-R criteria. Schizophrenia Bulletin, 17(4), 555-564. https://doi.org/10.1093/schbul/17.4.555.

Raine, A., \& Benishay, D. (1995). The SPQ-B: A brief screening instrument for schizotypal personality disorder. Journal of Personality Disorders, 9(4), 346-355. https://doi.org/10.1521/pedi.1995.9.4.346.

Raine, A., Reynolds, C., Lencz, T., Scerbo, A., Triphon, N., \& Kim, D. (1994). Cognitiveperceptual, interpersonal, and disorganized features of schizotypal personality. Schizophrenia Bulletin, 20(1), 191-201. https://doi.org/10.1093/schbul/20.1.191.

Rawlings, D., \& Freeman, J. L. (1997). Measuring paranoia/suspiciousness. In G. Claridge (Ed.), Schizotypy: Implications for illness and health. (pp. 38-60) Oxford University Press, Oxford, England. https://doi.org/10.1093/med:psych/9780198523536.003.0003.

Rawlings, D., \& Locarnini, A. (2008). Dimensional schizotypy, autism, and unusual word associations in artists and scientists. Journal of Research in Personality, 42(2), 465-471. https://doi.org/10.1016/j.jrp.2007.06.005.

Rominger, C., Papousek, I., Fink, A., \& Weiss, E. M. (2014). Enhancement of figural creativity by motor activation: effects of unilateral hand contractions on creativity are moderated by positive schizotypy. Laterality: Asymmetries of Body, Brain and Cognition, 19(4), 424-438. https://doi.org/10.1080/1357650x.2013.858725.

Russ, S. W. (1993). Affect and creativity: The role of affect and play in the creative process. Hillsdale, NJ: Erlbaum. https://doi.org/10.4324/9780203772621.

Rybakowski, J. K., \& Klonowska, P. (2011). Bipolar mood disorder, creativity and schizotypy: an experimental study. Psychopathology, 44(5), 296-302. https://doi.org/10.1159/000322814.

Salokangas, R. K. R., Dingemans, P., Heinimaa, M., Svirskis, T., Luutonen, S., Hietala, J., \& Birchwood, M. (2013). Prediction of psychosis in clinical high-risk patients by the Schizotypal Personality Questionnaire. Results of the EPOS project. European psychiatry, 28(8), 469-475. DOI: 10.1016/j.eurpsy.2013.01.001

Soler, J., Cebolla, A., Feliu-Soler, A., Demarzo, M. M., Pascual, J. C., Baños, R., \& GarcíaCampayo, J. (2014). Relationship between meditative practice and self-reported mindfulness: the MINDSENS composite index. PloS One, 9(1). https://doi.org/10.1371/journal.pone.0086622.

Wilcox, J., Briones, D., Quadri, S., \& Tsuang, M. (2014). Prognostic implications of paranoia and thought disorder in new onset psychosis. Comprehensive Psychiatry, 55(4), 813817. https://doi.org/10.1016/j.comppsych.2013.12.010.

Winston, C. N., Tarkas, N. J., \& Maher, H. (2014). Eccentric or egocentric? Preoperational features in schizotypic and creative adults. Psychology of Aesthetics, Creativity, and the Arts, 8(4), 413. https://doi.org/10.1037/a0037442. 
Zabelina, D. L., O’Leary, D., Pornpattananangkul, N., Nusslock, R., \& Beeman, M. (2015). Creativity and sensory gating indexed by the P50: Selective versus leaky sensory gating in divergent thinkers and creative achievers. Neuropsychologia, 69, 77-84.

https://doi.org/10.1016/j.neuropsychologia.2015.01.034.

Zabelina, D. L., \& Robinson, M. D. (2010). Creativity as flexible cognitive control. Psychology of Aesthetics, Creativity, and the Arts, 4(3), 13.

https://doi.org/10.1037/a0017379. 
Appendix: Supplementary Online Materials 
Table A.1. Cronbach's alpha for the current sample $(N=342)$, descriptions and item examples for the subscales of the SPQ (positive schizotypy dimension), $F F M Q$, and ECQ (Part A).

\begin{tabular}{|c|c|c|c|}
\hline Scale/Subscale & $\begin{array}{c}\text { Cronbach's } \\
\text { Alpha }\end{array}$ & Description & Item Example \\
\hline \multicolumn{4}{|l|}{ SPQ positive subscales } \\
\hline $\begin{array}{l}\text { Odd Beliefs/ Magical } \\
\text { Thinking }\end{array}$ & $a=.66$ & $\begin{array}{l}\text { Belief in the supernatural/paranormal, e.g., } \\
\text { telepathy. }\end{array}$ & $\begin{array}{l}\text { 'Are you sometimes sure that other people can } \\
\text { tell what you are thinking?' }\end{array}$ \\
\hline $\begin{array}{l}\text { Unusual Perceptual } \\
\text { Experiences }\end{array}$ & $a=.70$ & $\begin{array}{l}\text { Perceiving things which others don't, e.g., } \\
\text { hallucinations. }\end{array}$ & $\begin{array}{l}\text { 'Have you ever seen things invisible to other } \\
\text { people?' }\end{array}$ \\
\hline Ideas of Reference & $a=.79$ & $\begin{array}{l}\text { Attributing personal significance to external } \\
\text { events. }\end{array}$ & $\begin{array}{l}\text { 'When you see people talking to each other, do } \\
\text { you often wonder if they are talking about } \\
\text { you?' }\end{array}$ \\
\hline Suspiciousness & $a=.80$ & $\begin{array}{l}\text { Distrust of others, perceptions of threat from } \\
\text { others. }\end{array}$ & $\begin{array}{l}\text { 'Do you often pick up hidden threats or put- } \\
\text { downs from what people say or do?' }\end{array}$ \\
\hline \multicolumn{4}{|l|}{ FFMQ } \\
\hline Observing & $a=.81$ & $\begin{array}{l}\text { Noticing internal and external experiences (e.g., } \\
\text { thoughts, feelings, external sensory information } \\
\text { such as sounds and smells). }\end{array}$ & $\begin{array}{l}\text { 'I pay attention to sensations, such as the wind } \\
\text { in my hair or sun on my face.' }\end{array}$ \\
\hline Describing & $a=.88$ & Ability to label and describe internal experiences. & $\begin{array}{l}\text { 'I can usually describe how I feel at the } \\
\text { moment in considerable detail.' }\end{array}$ \\
\hline Acting with Awareness & $a=.86$ & $\begin{array}{l}\text { Attending, with awareness, to the present moment } \\
\text { or current activity (as opposed to 'running on } \\
\text { automatic pilot'). }\end{array}$ & $\begin{array}{l}\text { 'When I do things, my mind wanders off and } \\
\text { I'm easily distracted (reversed).' }\end{array}$ \\
\hline $\begin{array}{l}\text { Non-Judging } \\
\text { (of inner experience) }\end{array}$ & $a=.91$ & $\begin{array}{l}\text { Ability to bring a non-judgmental attitude to } \\
\text { thoughts and feelings. }\end{array}$ & $\begin{array}{l}\text { 'I make judgements about whether my } \\
\text { thoughts are good or bad (reversed).' }\end{array}$ \\
\hline $\begin{array}{l}\text { Non-Reacting } \\
\text { (to inner experience) }\end{array}$ & $a=.80$ & $\begin{array}{l}\text { Ability to not get caught up in thoughts and } \\
\text { feelings, letting them come and go as they occur. }\end{array}$ & $\begin{array}{l}\text { 'I perceive my feelings and emotions without } \\
\text { having to react to them.' }\end{array}$ \\
\hline \multicolumn{4}{|l|}{ ECQ Part A } \\
\hline Distinct Experience & $a=.82$ & $\begin{array}{l}\text { Creativity as a distinct experience compared to } \\
\text { everyday experience, including reduced self- } \\
\text { awareness and boundaries. }\end{array}$ & $\begin{array}{l}\text { 'I experienced relief that I was removed from } \\
\text { the world of everyday perception.' }\end{array}$ \\
\hline Anxiety & $a=.71$ & $\begin{array}{l}\text { A sense of vulnerability or anxiety associated } \\
\text { with the creative process. }\end{array}$ & $\begin{array}{l}\text { 'I believed strongly in what I was creating, } \\
\text { without doubting or questioning myself } \\
\text { (reversed).' }\end{array}$ \\
\hline Absorption & $a=.87$ & $\begin{array}{l}\text { A sense of being deeply absorbed in the creative } \\
\text { process. }\end{array}$ & $\begin{array}{l}\text { 'I lost awareness of time and my physical } \\
\text { surroundings.' }\end{array}$ \\
\hline Power/Pleasure & $a=.78$ & $\begin{array}{l}\text { Affective-related aspect, reflecting a sense of } \\
\text { pleasure and control during the creative process. }\end{array}$ & $\begin{array}{l}\text { 'It was characterised by intense feelings of joy } \\
\text { and satisfaction.' }\end{array}$ \\
\hline Clarity/Preparation & $a=.53$ & $\begin{array}{l}\text { A sense of certainty about which direction the } \\
\text { creative work will be taken, including the } \\
\text { preparation for the process. }\end{array}$ & $\begin{array}{l}\text { 'I put myself in the mood I wanted my creative } \\
\text { work to take on.' }\end{array}$ \\
\hline
\end{tabular}

Abbreviations: $\mathrm{ECQ}=$ Experience of Creativity Questionnaire $; \mathrm{FFMQ}=$ Five Facet Mindfulness

Questionnaire; $\mathrm{SPQ}=$ Schizotypal Personality Questionnaire 
Table A.2. Spearman correlations between the SPQ (positive schizotypy), FFMQ, and ECQ Part A with mean scores and standard deviations.

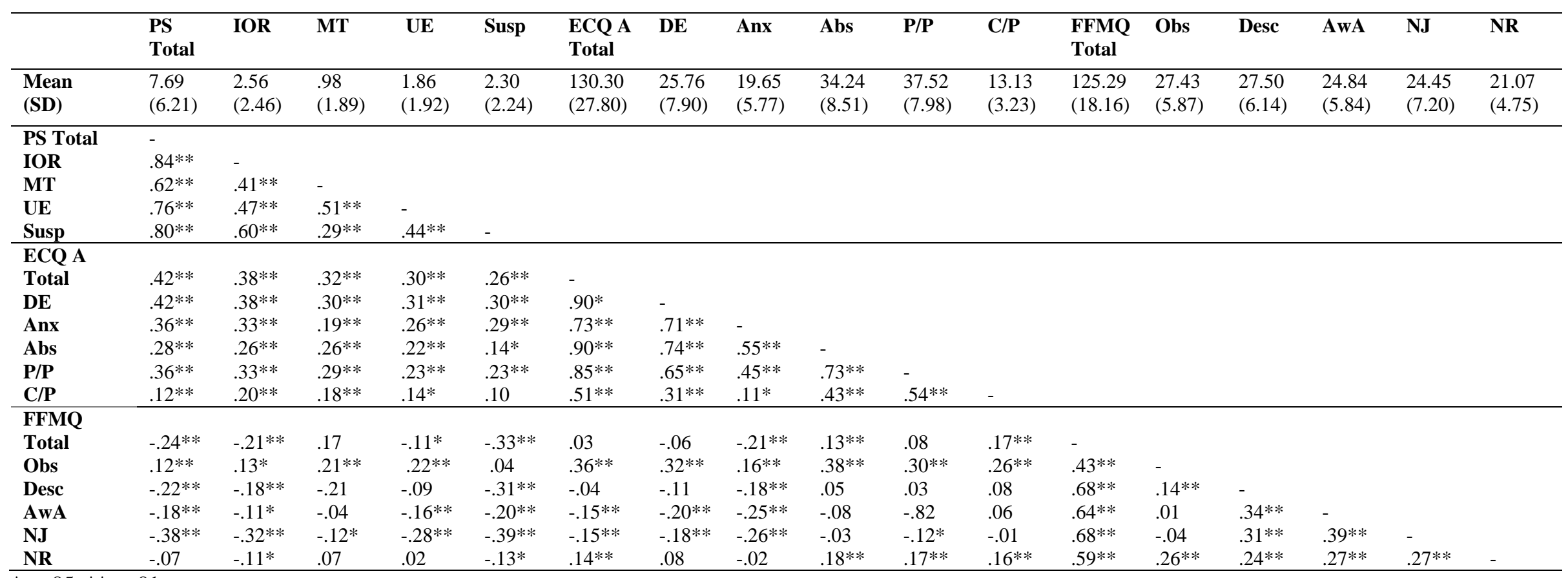

$* p<.05, * * p<.01$

Abbreviations: $\mathrm{ABS}=$ Absorption $; \mathrm{Anx}=$ Anxiety $; \mathrm{AwA}=$ Acting with Awareness $; \mathrm{C} / \mathrm{P}=$ Clarity $/$ Preparation $; \mathrm{DE}=$ Distinct Experience $;$ Desc $=$ Describing $; \mathrm{ECQ} \mathrm{A}$ Total = Experience of Creativity Questionnaire Part A Total $;$ FFMQ Total $=$ Five Facet Mindfulness Questionnaire Total $;$ IOR $=$ Ideas of Reference $;$ MT $=$ Magical Thinking; $\mathrm{NJ}=$ Non-judging $; \mathrm{NR}=$ Non-reacting; Obs = Observing; $\mathrm{P} / \mathrm{P}=$ Power/Pleasure $; \mathrm{PS}$ Total $=$ Positive Schizotypy Total $;$ Susp $=$ Suspiciousness. 
Table A.3. The results of all models testing the moderation effect of SPQ Suspiciousness on the relationship of SPQ Unusual Perceptual Experiences and Magical Thinking with the ECQ Part A factors.

\begin{tabular}{|c|c|c|c|c|}
\hline SPQ Factor & ECQ Facet & Predictors & $\beta(\mathrm{SE})$ & $p$ value $[95 \% \mathrm{CI}]$ \\
\hline Unusual & Distinct Experience & Unusual Perceptual Experiences & $1.19(.25)$ & $<.001[70,1.69]$ \\
\hline Perceptual & & Suspiciousness & $.59(.21)$ & $.006[.17,1.01]$ \\
\hline \multirow[t]{23}{*}{ Experiences } & & UnEx $x$ Susp & $-.11(.10)$ & $.26[-.30, .08]$ \\
\hline & & Constant & $25.97(.43)$ & $<.001[25.11,26.82]$ \\
\hline & & Model Summary & \multicolumn{2}{|c|}{$R^{2}=.14 ; F(3,338)=16.52, p<.001$} \\
\hline & Absorption & Unusual Perceptual Experiences & $1.05(.24)$ & $<.001[.59,1.52]$ \\
\hline & & Suspiciousness & $.17(.24)$ & $.47[-.29, .64]$ \\
\hline & & UnEx $x$ Susp & $-.18(.10)$ & $.08[-.39, .02]$ \\
\hline & & Constant & $43.58(.46)$ & $<.001[33.67,35.49]$ \\
\hline & & Model Summary & \multicolumn{2}{|c|}{$R^{2}=.06 ; F(3,338)=8.28, p<.001$} \\
\hline & Anxiety & Unusual Perceptual Experiences & $.71(.18)$ & $<.001[.35,1.07]$ \\
\hline & & Suspiciousness & $.47(.16)$ & $.003[.16, .78]$ \\
\hline & & UnEx $x$ Susp & $.06(.07)$ & $.39[-.19, .08]$ \\
\hline & & Constant & $19.76(.32)$ & $<.001[19.13,20.40]$ \\
\hline & & Model Summary & \multicolumn{2}{|c|}{$R^{2}=.12 ; F(3,338)=14.02, p<.001$} \\
\hline & Power/Pleasure & Unusual Perceptual Experiences & $.80(.23)$ & $<.001[.34,1.25]$ \\
\hline & & Suspiciousness & $.55(.23)$ & $.02[.10,1.00]$ \\
\hline & & UnEx $x$ Susp & $-.23(.09)$ & $.01[-.42,-.05]$ \\
\hline & & Constant & $37.95(.45)$ & $<.001[37.07,38.83]$ \\
\hline & & Model Summary & \multicolumn{2}{|c|}{$R^{2}=.08 ; F(3,338)=9.22, p<.001$} \\
\hline & Clarity/Preparation & Unusual Perceptual Experiences & $.27(.10)$ & $<.01[-.07, .48]$ \\
\hline & & Suspiciousness & $.07(.09)$ & $.44[-.11, .26]$ \\
\hline & & UnEx $x$ Susp & $.07(.04)$ & $.06[-.15, .00]$ \\
\hline & & Constant & $13.27(.19)$ & $<.001[12.89,13.64]$ \\
\hline & & Model Summary & \multicolumn{2}{|c|}{$R^{2}=.03 ; F(3,338)=3.97, p=.008$} \\
\hline Magical & Distinct Experience & Magical Thinking & $1.42(.33)$ & $<.001[.77,2.07]$ \\
\hline \multirow{24}{*}{ Thinking } & & Suspiciousness & $.77(.20)$ & $<.001[.38,1.17]$ \\
\hline & & MT x Susp & $-.14(.17)$ & $.41[-.48, .20]$ \\
\hline & & Constant & $25.86(.42)$ & $<.001[25.04,26.68]$ \\
\hline & & Model Summary & \multicolumn{2}{|c|}{$R^{2}=.13 ; F(3,338)=14.86, p<.001$} \\
\hline & Absorption & Magical Thinking & $1.42(.30)$ & $<.001[.84,2.01]$ \\
\hline & & Suspiciousness & $.25(.22)$ & $.25[-.18, .68]$ \\
\hline & & MT $x$ Susp & $-.16(.25)$ & $.30[-.45, .14]$ \\
\hline & & Constant & $34.35(.45)$ & $<.001[33.47,35.23]$ \\
\hline & & Model Summary & \multicolumn{2}{|c|}{$R^{2}=.06 ; F(3,338)=9.20, p<.001$} \\
\hline & Anxiety & Magical Thinking & $.56(.21)$ & $.007[.15, .96]$ \\
\hline & & Suspiciousness & $.62(.14)$ & $<.001[.34, .09]$ \\
\hline & & MT $x$ Susp & $.00(.11)$ & $.98[-.21, .22]$ \\
\hline & & Constant & $19.65(.30)$ & $<.001[19.06,20.24]$ \\
\hline & & Model Summary & \multicolumn{2}{|c|}{$R^{2}=.09 ; F(3,338)=9.81, p<.001$} \\
\hline & Power/Pleasure & Magical Thinking & $1.52(.29)$ & $<.001[.96,2.08]$ \\
\hline & & Suspiciousness & $.50(.20)$ & $.02[.10, .90]$ \\
\hline & & MT x Susp & $-.29(.13)$ & $.03[-.54 .-.03]$ \\
\hline & & Constant & $37.72(.42)$ & $<.001[.36 .90,38.54]$ \\
\hline & & Model Summary & \multicolumn{2}{|c|}{$R^{2}=.11 ; F(3,338)=13.91, p<.001$} \\
\hline & Clarity/Preparation & Magical Thinking & $.39(.13)$ & $.003[.13, .65]$ \\
\hline & & Suspiciousness & $.07(.08)$ & $.40[-.09, .23]$ \\
\hline & & MT $x$ Susp & $-.02(.06)$ & $.71[-.14, .09]$ \\
\hline & & Constant & $13.14(.18)$ & $<.001[12.79,13.50]$ \\
\hline & & Model Summary & \multicolumn{2}{|c|}{$R^{2}=.03 ; F(3,338)=3.87, p=.009$} \\
\hline
\end{tabular}

Abbreviations: $\mathrm{ECQ}=$ Experience of Creativity Questionnaire; $\mathrm{MT}=$ Magical Thinking; $\mathrm{SPQ}=$ Schizotypal Personality Questionnaire; Susp = Suspiciousness . 
Table A.4. Full results of multiple linear regression analysis testing the interaction effects between FFMQ facet scores and conglomerate scores for SPQ Magical Thinking + Unusual Experiences vs. Suspiciousness + Ideas of Reference on predicting ECQ factor scores.

\begin{tabular}{|c|c|c|c|c|c|c|c|c|c|c|c|}
\hline \multicolumn{12}{|c|}{ ECQ Factor } \\
\hline & $\begin{array}{l}\text { Predictor } \\
\text { Variable }\end{array}$ & \multicolumn{2}{|c|}{ Distinct Experience } & \multicolumn{2}{|c|}{ Anxiety } & \multicolumn{2}{|c|}{ Absorption } & \multicolumn{2}{|c|}{ Power/Pleasure } & \multicolumn{2}{|c|}{ Clarity/Preparation } \\
\hline FFMQ Facet & & $\beta(\mathrm{SE})$ & $95 \% \mathrm{CI}$ & $\beta(\mathrm{SE})$ & $95 \% \mathrm{CI}$ & $\beta(\mathrm{SE})$ & $95 \% \mathrm{CI}$ & $\beta$ (SE) & $95 \% \mathrm{CI}$ & $\beta(\mathrm{SE})$ & $95 \% \mathrm{CI}$ \\
\hline \multirow[t]{6}{*}{ Observing } & MTUE & $.56 * *(.20)$ & {$[.1 \beta 4, .93]$} & $.28 *(.13)$ & {$[.02, .53]$} & $.47 *(.20)$ & {$[.07, .85]$} & $.39 *(.18)$ & {$[.03, .72]$} & $.09(.07)$ & {$[-.05, .24]$} \\
\hline & SuspIoR & $.42 * *(.11)$ & {$[.20, .64]$} & $.33 * *(.08)$ & {$[.17, .49]$} & $.16(.12)$ & {$[-.08, .40]$} & $.34 * *(.12)$ & {$[.12, .57]$} & $.08(.05)$ & {$[-.01, .17]$} \\
\hline & FFMQ Obs & $.33 * *(.07)$ & {$[.20,48]$} & $.12 *(.05)$ & {$[.02, .23]$} & $.48 * *(.07)$ & {$[.34, .62]$} & $.34 * *(.07)$ & {$[.21, .48]$} & $.12 * *(.03)$ & {$[.07, .18]$} \\
\hline & MTUE $x \mathrm{Obs}$ & $-.02(.04)$ & {$[-.08, .05]$} & $2.81(.02)$ & {$[-.04, .04]$} & $-.04(.03)$ & {$[-.10, .03]$} & $-.05(.03)$ & {$[-.11, .01]$} & $-.01(.01)$ & {$[-.03, .02]$} \\
\hline & SuspIoR x Obs & $.00(.02)$ & {$[-.03, .05]$} & $.00(.01)$ & {$[-.02, .03]$} & $-.01(.02)$ & {$[-.05, .03]$} & $-.01(.02)$ & {$[-.05, .03]$} & $-.00(.01)$ & {$[-.02, .01]$} \\
\hline & Model Summary & \multicolumn{2}{|c|}{$\begin{array}{c}\text { Adjusted } R^{2}=.22 \\
F(5,336)=20.59, p<.001\end{array}$} & \multicolumn{2}{|c|}{$\begin{array}{c}\text { Adjusted } R^{2}=.13 \\
F(5,336)=11, p<.001\end{array}$} & \multicolumn{2}{|c|}{$\begin{array}{c}\text { Adjusted } R^{2}=.19 \\
F(5,336)=16.58, p<.001\end{array}$} & \multicolumn{2}{|c|}{$\begin{array}{c}\text { Adjusted } R^{2}=.18 \\
F(5,336)=15.67, p<.001\end{array}$} & \multicolumn{2}{|c|}{$\begin{array}{c}\text { Adjusted } R^{2}=.08, \\
F(5,336)=7.16, p<.001\end{array}$} \\
\hline \multirow[t]{6}{*}{ Describing } & MTUE & $.72 * *(.17)$ & {$[.38,1.06]$} & $.37 * *(.12)$ & {$[.14, .61]$} & $.66^{* *}(.18)$ & {$[.31,1.01]$} & $.48 * *(.16)$ & {$[.18, .79]$} & $.14 *(.07)$ & {$[.01, .28]$} \\
\hline & SuspIoR & $.42 * *(.12)$ & {$[.20, .65]$} & $.29 * *(.09)$ & {$[-.12,-.46]$} & $.23(.13)$ & {$[-.02, .47]$} & $.42 * *(.11)$ & {$[.20, .64]$} & $.12 * *(.05)$ & {$[.02, .21]$} \\
\hline & FFMQ Desc & $-.05(.07)$ & {$[-.18, .08]$} & $-.11 *(.06)$ & {$[-.22,-.01]$} & $.11(.08)$ & {$[-.05, .27]$} & $.12(.07)$ & {$[-.02, .26]$} & $.06 *(.03)$ & {$[.01, .11]$} \\
\hline & MTUE $x$ Desc & $.00(.03)$ & {$[-.05, .06]$} & $-.02(.02)$ & {$[-.06, .02]$} & $.03(03)$ & {$[-.03, .08]$} & $.06 *(.03)$ & {$[.01, .11]$} & $.01(.01)$ & {$[-.01, .03]$} \\
\hline & SuspIoR $x$ Desc & $.03(.02)$ & {$[-.01, .06]$} & $.03 *(.01)$ & {$[-.00, .06]$} & $.01(.02)$ & {$[-.03, .05]$} & $-.01(.02)$ & {$[-.05, .03]$} & $.01(.01)$ & {$[-.01, .02]$} \\
\hline & Model Summary & \multicolumn{2}{|c|}{$\begin{array}{c}\text { Adjusted } R^{2}=.17 \\
F(5,336)=14.99, p<.001\end{array}$} & \multicolumn{2}{|c|}{$\begin{array}{c}\text { Adjusted } R^{2}=.14, \\
F(5,336)=11.82, p<.001\end{array}$} & \multicolumn{2}{|c|}{$\begin{array}{c}\text { Adjusted } R^{2}=.07 \\
F(5,336)=6.39, p<.001\end{array}$} & \multicolumn{2}{|c|}{$\begin{array}{c}\text { Adjusted } R^{2}=.11 \\
F(5,336)=9.41, p<.001\end{array}$} & \multicolumn{2}{|c|}{$\begin{array}{c}\text { Adjusted } R^{2}=.05, \\
F(5,336)=4.63, p<.001\end{array}$} \\
\hline \multirow{6}{*}{$\begin{array}{l}\text { Acting with } \\
\text { Awareness } \\
(A w A)\end{array}$} & MTUE & $.70 * *(.17)$ & {$[.35,1.03]$} & $.27 *(.12)$ & {$[.03, .50]$} & $.74 * *(.17)$ & {$[.40,1.07]$} & $.57 * *(.17)$ & {$[.24, .90]$} & $.22 * *(.07)$ & {$[.08, .36]$} \\
\hline & SuspIoR & $.38 * *(.12)$ & {$[.16, .61]$} & $.31 * *(.09)$ & {$[.15, .50]$} & $.13(.13)$ & {$[-.12, .38]$} & $.35^{* *}(.12)$ & {$[.12, .57]$} & $.07(.05)$ & {$[-.02, .17]$} \\
\hline & $A W A$ & $-.17 *(.07)$ & {$[-.31,-.03]$} & $-.17 * *(.06)$ & {$[-.28,-.06]$} & $-.07(.09)$ & {$[-.23, .10]$} & $-.04(.08)$ & {$[-.19, .12]$} & $.06(.03)$ & {$[-.01, .11]$} \\
\hline & MTUE $x A w A$ & $.01(.03)$ & {$[-.04, .07]$} & $-.03(.02)$ & {$[-.06,0.1]$} & $.04(.03)$ & {$[-.02, .11]$} & $.04(.03)$ & {$[-.01, .10]$} & $.03 * *(.01)$ & {$[.01, .05]$} \\
\hline & SuspIoR $x A w A$ & $.01(.02)$ & {$[-.03, .05]$} & $.02(.02)$ & {$[-.01, .05]$} & $-.01(.02)$ & {$[-.05, .04]$} & $.01(.02)$ & {$[-.03, .05]$} & $-.01(.01)$ & {$[-.02, .01]$} \\
\hline & Model Summary & \multicolumn{2}{|c|}{$\begin{array}{c}\text { Adjusted } R^{2}=.18 \\
F(5,336)=15.97, p<.001\end{array}$} & \multicolumn{2}{|c|}{$\begin{array}{c}\text { Adjusted } R^{2}=.15 \\
F(5,336)=13.03, p<.001\end{array}$} & \multicolumn{2}{|c|}{$\begin{array}{c}\text { Adjusted } R^{2}=.07 \\
F(5,336)=6.21, p<.001\end{array}$} & \multicolumn{2}{|c|}{$\begin{array}{c}\text { Adjusted } R^{2}=.10 \\
F(5,336)=8.75, p<.001\end{array}$} & \multicolumn{2}{|c|}{$\begin{array}{c}\text { Adjusted } R^{2}=.06 \\
F(5,336)=5, p<.001\end{array}$} \\
\hline \multirow{4}{*}{$\begin{array}{l}\text { Non-Judging } \\
(N J)\end{array}$} & MTUE & $.69 * *(.18)$ & {$[.34,1.04]$} & $.32 * *(.12)$ & {$[.08, .55]$} & $.71 * *(.18)$ & {$[.35,1.06]$} & $.53 * *(.17)$ & {$[.20, .86]$} & $.17 *(.07)$ & {$[.02, .31]$} \\
\hline & SuspIoR & $.43 * *(.12)$ & {$[.20, .67]$} & $.26 * *(.09)$ & {$[.09, .43]$} & $.17(.14)$ & {$[-.09, .44]$} & $.39 * *(.12)$ & {$[.15, .63]$} & $.10 *(.05)$ & {$[.00, .20]$} \\
\hline & $N J$ & $-.03(.05)$ & {$[-.14, .08]$} & $-.13 * *(.05)$ & {$[-.22,-.04]$} & $.03(.07]$ & {$[-.10, .17]$} & $.01(.07)$ & {$[-.12, .14]$} & $.03(.03)$ & {$[-.03, .08]$} \\
\hline & MTUE $x$ NJ & $\begin{array}{l}-.01(.02) \\
02(02)\end{array}$ & {$[-.05, .03]$} & $-.01(.02)$ & {$[-.04, .03]$} & $.02(.02)$ & {$[-.02, .06]$} & $.02(.02)$ & {$[-.03, .06]$} & $.01(.01)$ & {$[-.01, .03]$} \\
\hline
\end{tabular}




\begin{tabular}{|c|c|c|c|c|c|c|c|c|c|c|c|}
\hline \multirow{3}{*}{$\begin{array}{l}\text { Non-Reacting } \\
\text { (NR) }\end{array}$} & \multirow{2}{*}{$\begin{array}{l}\text { Model Summary } \\
\text { MTUE }\end{array}$} & \multicolumn{2}{|c|}{$\begin{array}{c}\text { Adjusted } R^{2}=.17, \\
F(5,336)=14.72, p<.001\end{array}$} & \multicolumn{2}{|c|}{$\begin{array}{c}\text { Adjusted } R^{2}=.14, \\
F(5,336)=12.20, p<.001\end{array}$} & \multicolumn{2}{|c|}{$\begin{array}{c}\text { Adjusted } R^{2}=.06, \\
F(5,336)=5.64, p<.001\end{array}$} & \multicolumn{2}{|c|}{$\begin{array}{c}\text { Adjusted } R^{2}=.10, \\
F(5,336)=8.44, p<.001\end{array}$} & \multicolumn{2}{|c|}{$\begin{array}{c}\text { Adjusted } R^{2}=.04, \\
F(5,336)=3.54, p=.004\end{array}$} \\
\hline & & $.69 * *(.17)$ & {$[.35,1.01]$} & $.37 * *(.12)$ & {$[.14, .60]$} & $.61 * *(.17)$ & {$[.26, .95]$} & $.44 * *(.16)$ & {$[.13, .74]$} & $.12(.07)$ & {$[-.01, .26]$} \\
\hline & SuspIoR & $.44 * *(.12)$ & {$[.22, .67]$} & $.32 * *(.08)$ & {$[.16, .48]$} & $.23(.12)$ & {$[-.01, .47]$} & $.43 * *(.11)$ & {$[.21, .64]$} & $.11 *(.05)$ & {$[.02, .20]$} \\
\hline & $N R$ & $.14(.09)$ & {$[-.02, .32]$} & $-.02(.06)$ & {$[-.15, .10]$} & $.35 * *(.09)$ & {$[.17, .53]$} & $.35 * *(.08)$ & {$[.19, .51]$} & $.13 * *(.04)$ & {$[.06, .20]$} \\
\hline & MTUE $\times N R$ & $-.03(.04)$ & {$[-.09, .05]$} & $-.06 * *(.02)$ & {$[-.11,-.02]$} & $-.04(.03)$ & {$[-.09, .03]$} & $-.02(.03)$ & {$[-.07, .05]$} & $-8.19(.02)$ & {$[-.03, .03]$} \\
\hline & SuspIoR $x$ NR & $-.01(.03)$ & {$[-.06, .04]$} & $.03(.02)$ & {$[-.01, .06]$} & $-.01(.02)$ & {$[-.06, .04]$} & $-.03(.02)$ & {$[-.07, .01]$} & $-.01(.01)$ & {$[-.03, .01]$} \\
\hline & Model Summary & \multicolumn{2}{|c|}{$\begin{array}{c}\text { Adjusted } R^{2}=.17 \\
F(5,336)=15.17, p<.001\end{array}$} & \multicolumn{2}{|c|}{$\begin{array}{c}\text { Adjusted } R^{2}=.13 \\
F(5,336)=11.19, p<.001\end{array}$} & \multicolumn{2}{|c|}{$\begin{array}{c}\text { Adjusted } R^{2}=.11, \\
F(5,336)=9.13, p<.001\end{array}$} & \multicolumn{2}{|c|}{$\begin{array}{c}\text { Adjusted } R^{2}=.14, \\
F(5,336)=12.31, p<.001\end{array}$} & \multicolumn{2}{|c|}{$\begin{array}{c}\text { Adjusted } R^{2}=.07 \\
F(5,336)=5.72, p<.001\end{array}$} \\
\hline
\end{tabular}

Abbreviations: AwA = Acting with Awareness; ECQ = Experience of Creativity Questionnaire; FFMQ = Five Facet Mindfulness Questionnaire; MTUE = Magical Thinking + Unusual Perceptual Experiences conglomerate scores; NJ = Non-Judging; NR = Non-Reacting; OBS = Observing; SuspIoR = Suspiciousness + Ideas of Reference conglomerate scores. 
Table A.5. The results of the independent $t$-tests for the differences in ECQ Part A \& B factor scores between the subsamples who reported being regularly engaged in creative activity (either as hobby, study, or profession) and those who did not.

\begin{tabular}{lcccc}
\hline & $\begin{array}{c}\text { Creatively } \\
\text { Active } \\
(\mathrm{n}=137)\end{array}$ & $\begin{array}{c}\text { Not Creatively } \\
\text { Active } \\
(\mathrm{n}=205)\end{array}$ & $\boldsymbol{t}$-statistic & Cohen's $\boldsymbol{d}$ \\
\hline Mean (SD) & Mean (SD) & $\boldsymbol{p}<. \mathbf{0 0 1}$ & \\
\hline ECQ Part A Factor & & & & \\
$\quad$ Distinct Experience & $28.76(7.30)$ & $23.76(7.29)$ & 6.04 & .69 \\
Anxiety & $21.45(5.80)$ & $18.45(5.46)$ & 4.86 & .53 \\
Absorption & $37.93(6.76)$ & $31.78(8.69)$ & 7.35 & .79 \\
Power/Pleasure & $40.55(7.43)$ & $35.50(7.70)$ & 6.03 & .75 \\
Clarity/Preparation & $13.92(2.86)$ & $12.60(3.36)$ & 3.78 & .42 \\
ECQ Part B Factor & & & & \\
Transformation & $26.61(5.42)$ & $23.06(6.19)$ & 5.47 & .61 \\
Centrality & $30.36(7.40)$ & $24.63(7.05)$ & 7.21 & .79 \\
Beyond the & $9.92(2.79)$ & $7.60(3.03)$ & 7.19 & .77 \\
Personal & & & & \\
\hline
\end{tabular}


Table A.6. The results of the independent $t$-tests for the differences in SPQ scores between the subsamples who reported being regularly engaged in creative activity (either as hobby, study, or profession) and those who did not.

\begin{tabular}{lcccc}
\hline & $\begin{array}{c}\text { Creatively } \\
\text { Active } \\
(\mathrm{n}=137)\end{array}$ & $\begin{array}{c}\text { Not Creatively } \\
\text { Active } \\
(\mathrm{n}=205)\end{array}$ & t-statistic & Cohen's $\boldsymbol{d}$ \\
\hline & Mean (SD) & Mean (SD) & & \\
\hline SPQ Total & $22.04(12.14)$ & $19.66(13.63)$ & 1.65 & .18 \\
SPQ Positive Schizotypy Subscale & & & & \\
$\quad$ Odd Beliefs/Magical Thinking & $1.34(1.59)$ & $.75(1.17)$ & $3.72 * * *$ & .42 \\
$\quad$ Unusual Perceptual Experiences & $2.13(2.07)$ & $1.68(1.80)$ & $2.09 *$ & .23 \\
$\quad \begin{array}{l}\text { Ideas of Reference } \\
\text { Suspiciousness }\end{array}$ & $2.93(2.47)$ & $2.29(2.42)$ & $2.36^{*}$ & .26 \\
& $2.37(2.20)$ & $2.26(2.27)$ & .459 & .05 \\
Total Positive Schizotypy & $8.77(6.22)$ & $6.98(6.12)$ & $2.64 * *$ & .29 \\
\hline$* p<.05, * * p<.01, * * * p<.001$ & & & &
\end{tabular}


Fig. A.1. The diagram of correlations between: a) SPQ positive schizotypy subscales and ECQ factors; b) SPQ positive schizotypy subscales and FFMQ facets; and c) FFMQ facets of the and ECQ factors.

a)

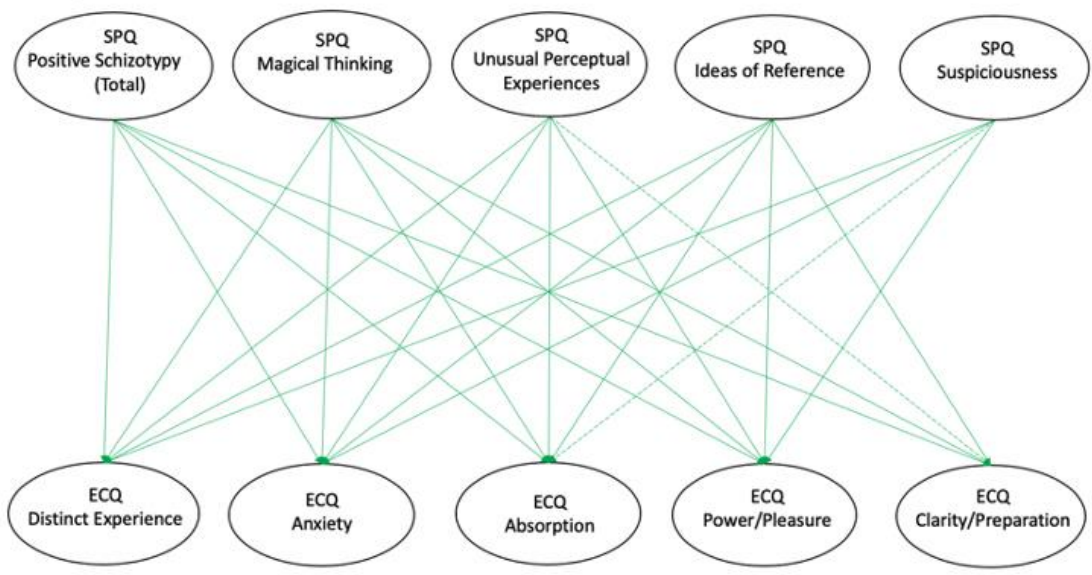

c)

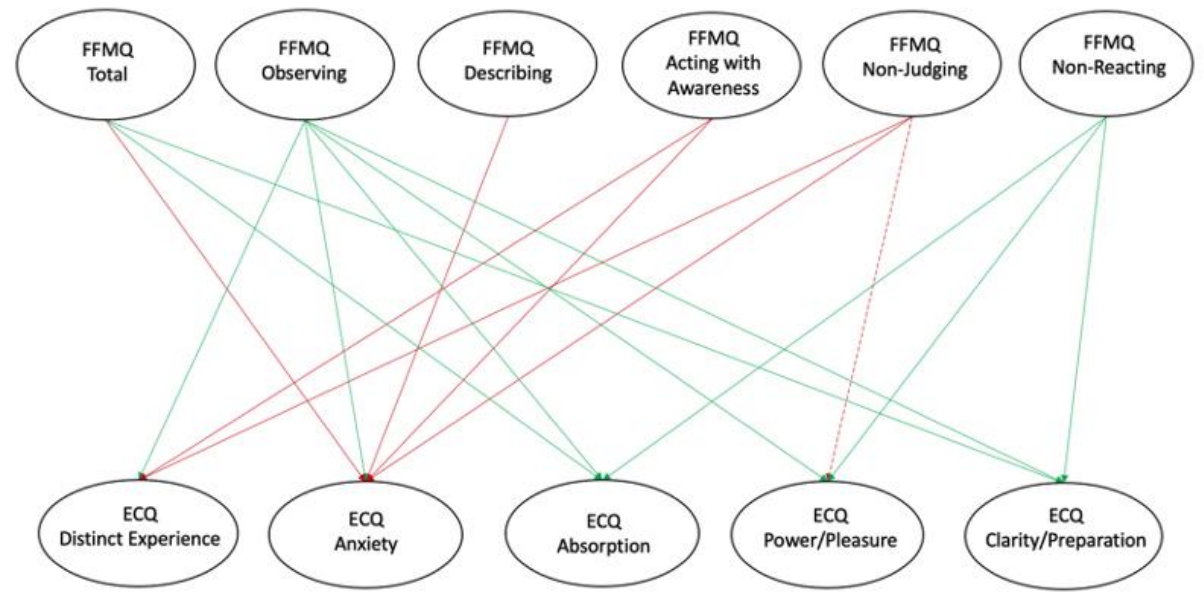

b)

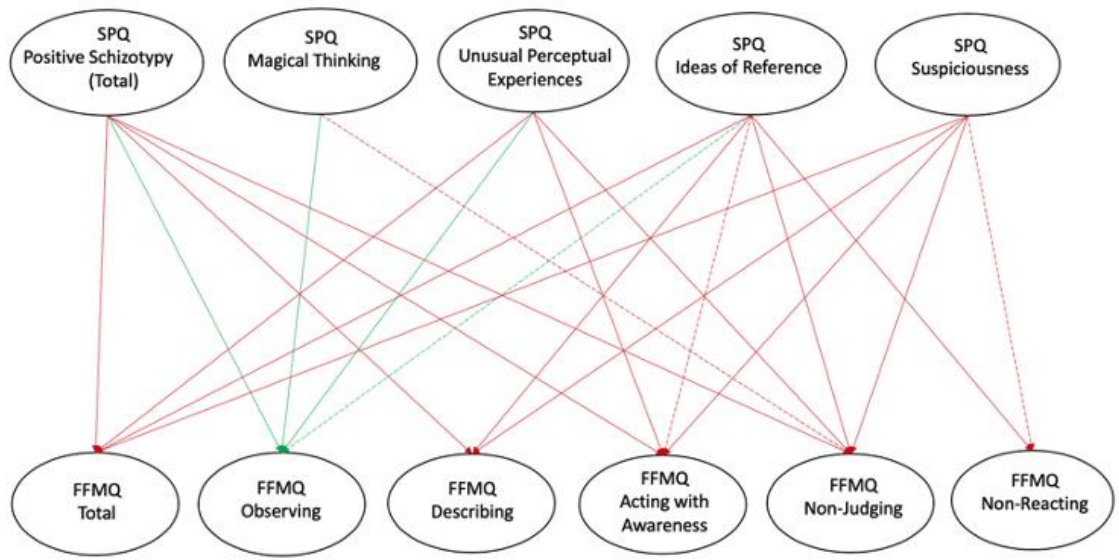


Fig. A.2. Scatter plots of the raw data demonstrating significant interactions between conglomerate scores for Magical Thinking + Unusual Perceptual Experiences (MTUE) and FFMQ facets in predicting ECQ factor scores: a) Anxiety, b) Clarity/Preparation; c) Power/Pleasure; and d) conglomerate scores for Suspiciousness + Ideas of Reference (SuspIoR) and FFMQ facet Describing in predicting ECQ factor Anxiety for the sub-groups with low, mean, and high scores on the respective FFMQ facets.
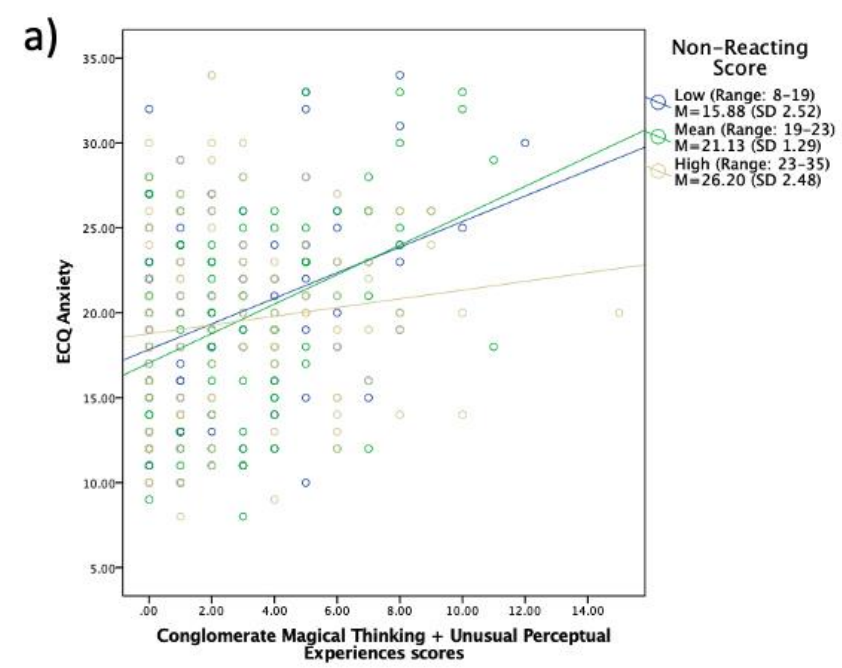

b)
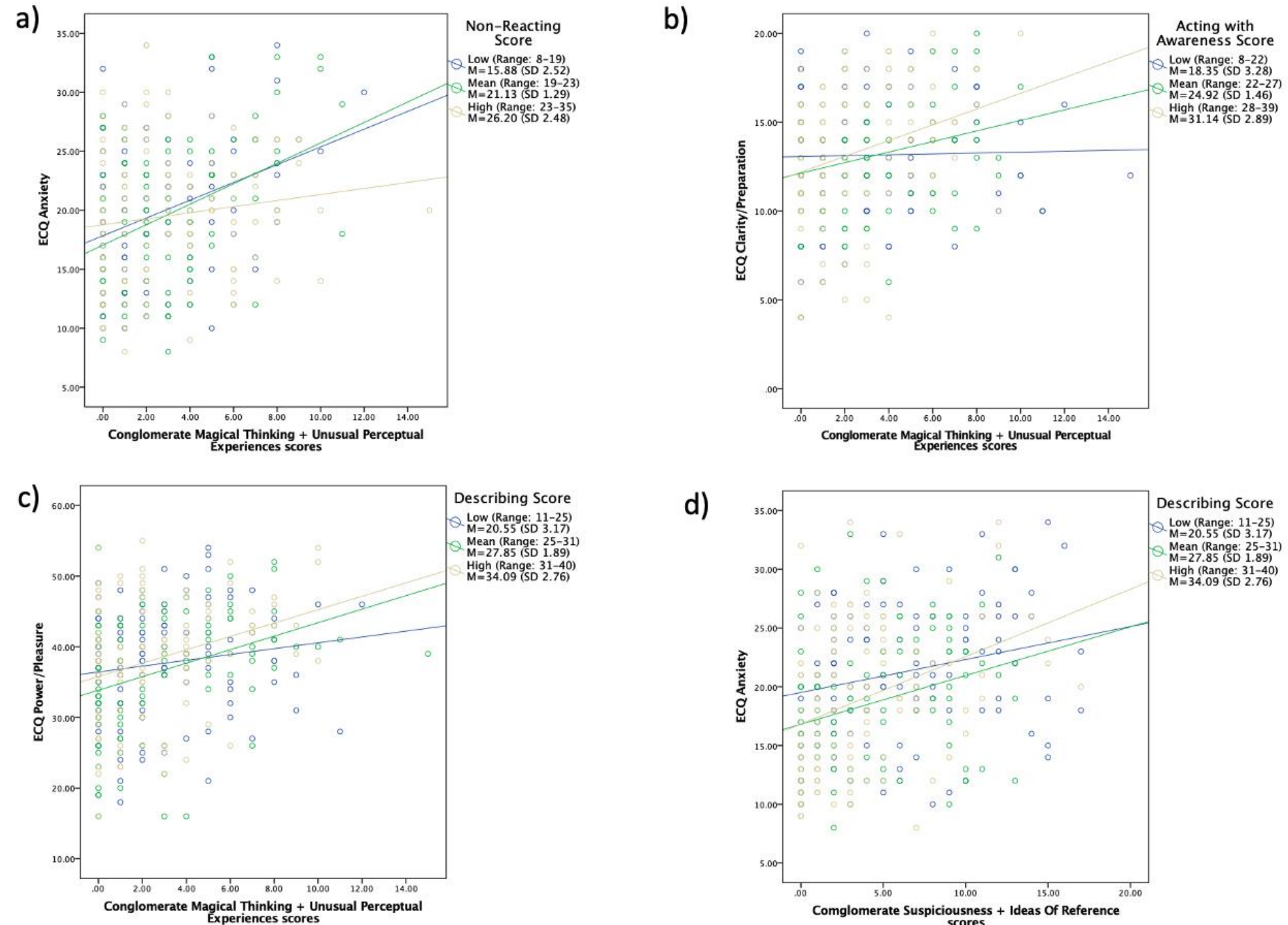

d)

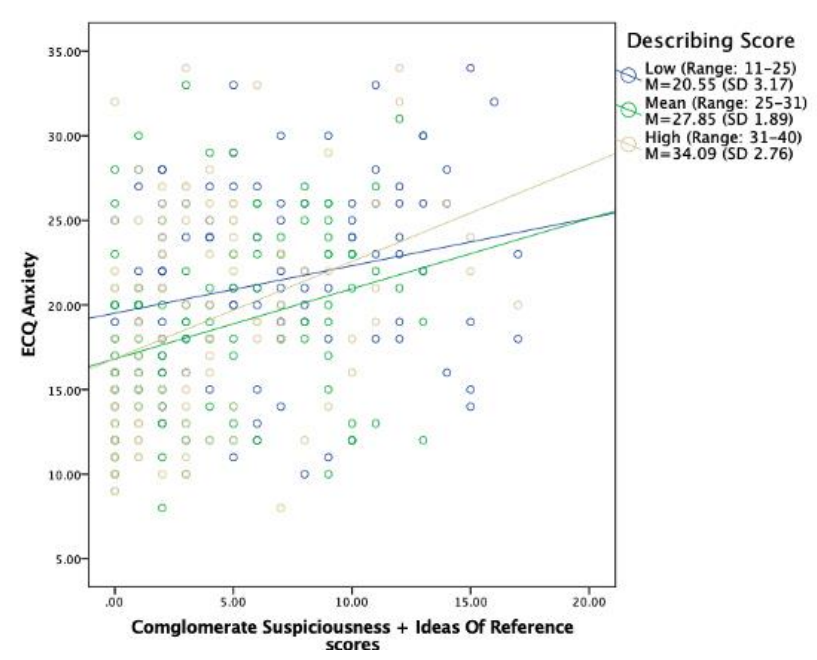

